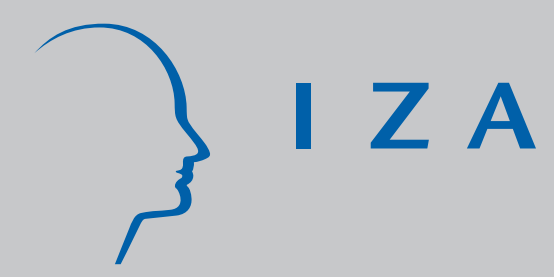

IZA DP No. 485

Class-Size Effects in School Systems Around the World:

Evidence from Between-Grade Variation in TIMSS

Ludger Woessmann

Martin R. West

April 2002 


\title{
Class-Size Effects in School Systems Around the World: Evidence from Between-Grade Variation in TIMSS
}

\author{
Ludger Woessmann \\ Kiel Institute for World Economics and IZA, Bonn \\ Martin R. West \\ Harvard University
}

Discussion Paper No. 485
April 2002

IZA

P.O. Box 7240

D-53072 Bonn

Germany

Tel.: +49-228-3894-0

Fax: +49-228-3894-210

Email: iza@iza.org

This Discussion Paper is issued within the framework of IZA's research area The Future of Labor. Any opinions expressed here are those of the author(s) and not those of the institute. Research disseminated by IZA may include views on policy, but the institute itself takes no institutional policy positions.

The Institute for the Study of Labor (IZA) in Bonn is a local and virtual international research center and a place of communication between science, politics and business. IZA is an independent, nonprofit limited liability company (Gesellschaft mit beschränkter Haftung) supported by the Deutsche Post AG. The center is associated with the University of Bonn and offers a stimulating research environment through its research networks, research support, and visitors and doctoral programs. IZA engages in (i) original and internationally competitive research in all fields of labor economics, (ii) development of policy concepts, and (iii) dissemination of research results and concepts to the interested public. The current research program deals with (1) mobility and flexibility of labor, (2) internationalization of labor markets, (3) welfare state and labor markets, (4) labor markets in transition countries, (5) the future of labor, (6) evaluation of labor market policies and projects and (7) general labor economics.

IZA Discussion Papers often represent preliminary work and are circulated to encourage discussion. Citation of such a paper should account for its provisional character. A revised version may be available on the IZA website (www.iza.org) or directly from the author. 


\section{ABSTRACT \\ Class-Size Effects in School Systems Around the World: Evidence from Between-Grade Variation in TIMSS*}

We estimate the effect of class size on student performance in 18 countries, combining school fixed effects and instrumental variables to identify random class-size variation between two adjacent grades within individual schools. Conventional estimates of class-size effects are shown to be severely biased by the non-random placement of students between and within schools. Smaller classes exhibit beneficial effects only in countries with relatively low teacher salaries. While we find sizable beneficial effects of smaller classes in Greece and Iceland, the possibility of even small effects is rejected in Japan and Singapore. In 11 countries, we rule out large class-size effects.

JEL Classification: $\quad 12$

Keywords: educational production, class size, student sorting, school fixed effects, instrumental variables, TIMSS

Ludger Woessmann

Kiel Institute for World Economics

Duesternbrooker Weg 120

24105 Kiel

Germany

Tel.: +49 $4318814-497$

Fax: $+494318814-500$

Email: woessmann@ifw.uni-kiel.de

\footnotetext{
* We would like to thank Sveinn Agnarsson (University of Iceland) and George Psacharopoulos (University of Athens) for sharing their knowledge of their respective countries' school systems, and Paul E. Peterson and Erich Gundlach for their comments on the manuscript. One author would like to thank the Program on Education Policy and Governance (PEPG) at the Kennedy School of Government, Harvard University, and the National Bureau of Economic Research (NBER) for their hospitality during his stay in Cambridge, Mass., during which the main work on this paper was completed.
} 


\section{Introduction}

School systems around the world differ in many respects. Important sources of variation include examination systems, the existence of high-stakes incentives for students and teachers, the provision of remedial instruction for lagging students or of enrichment classes for outstanding students, the level and allocation of resources, the quality of the teaching force, and average class size. Given these differences, it is not obvious that findings from any particular school system translate directly into general principles for all systems. Although the effect of class size on student achievement in the United States has recently been the subject of a great deal of research, the U.S. findings simply may not generalize to school systems in other parts of the world with distinctive institutional configurations. This paper explores this possibility by providing estimates of class-size effects in 18 education systems scattered across four continents.

The central problem in estimating class-size effects is that placement decisions made by parents and schools obscure the causal relationship between class size and student performance. For example, parents may place children in schools with bigger or smaller class sizes on the basis of their educational performance; administrative rules may track students into different schools depending on their achievement; and individual educators may sort students within a school into differently sized classes according to their behavior or demonstrated academic potential. As a result, naïve estimates of education production functions may be biased both by endogeneity of class size with respect to student performance and by omitted variables. Estimating "true" class-size effects, i.e. the causal effect of class size on student performance, thus requires an identification strategy that restricts the analysis to exogenous variations in class size, thereby allowing for the causal class-size effect to be disentangled from the effects of sorting.

In principle, two such strategies are available. The first is to conduct an experiment, using random assignment of students to classrooms to ensure that all variation in class size is exogenous. The second is to adopt a quasi-experimental approach in which instrumental variable (IV) estimates are used to restrict the analysis to that part of the total variation in class size that is exogenous to student achievement. 
Evidence from the one large-scale random-assignment experiment on class-size effects, the Tennessee Student/Teacher Achievement Ratio experiment ("Project STAR"), has been analyzed both in terms of its initial impact on student achievement (Krueger 1999) and in its longer-term consequences for academic progress (Krueger and Whitmore 2001). Unfortunately, however, the validity of this experiment may actually have been undermined by specific decentralized placement decisions; nonrandom parental choices prior to the start of the experiment - e.g. not to send their children to participating schools if they were assigned to larger classes - cannot be ruled out and would bias any estimate of class-size effects. Several other issues of design and implementation of Project STAR also call into question the validity of its results (Hanushek 1999). Furthermore, any experiment suffers from the so-called "Hawthorne effect" in that participants are aware that they are being evaluated, and may respond by increasing their effort. Knowledge of one's participation in an experiment can also alter the prevailing incentive conditions in important ways. For example, the schools participating in Project STAR may have realized that their future resource endowments would be affected by the outcome of the experiment, and may have adjusted their behavior accordingly (Hoxby 2000). In short, the use of randomized experiments to assess the effects of class size has intrinsic problems, and the implementation of the one major class-size experiment seems to have been less than optimal. And it must be recalled that we have evidence from only one experiment, conducted in a single U.S. state in the mid-eighties. The near universal popularity of country music notwithstanding, the situation in Tennessee simply may not be representative of school systems in other parts of the world.

Studies using quasi-experimental evidence also have important disadvantages. Principle among them is the need to examine rather specific variations in class size that make it possible to disentangle the causal effect of class size on student achievement from the results of sorting. As a consequence, studies using this kind of identification strategy are also only available for a few countries and situations. Angrist and Lavy (1999) exploit a specific rule on maximum class size in Israel to extract presumably exogenous variation in Israeli class sizes. While this identification strategy excludes class-size variations due to student assignments within a school, it is not immune to bias from parental residential choice. Moreover, they are only able to analyze the effects of 
variation in class size between 20 and 40 students, which may not be the range most of interest to policy-makers in many countries. Case and Deaton (1999) identify class-size effects by looking at data on black students in South Africa during apartheid, arguing that the variation in class sizes for black students was largely exogenous, because the black population at this time had neither freedom of residential choice nor control over their schools' endowments. But the South African school system during apartheid was obviously unique in its institutional configuration, and was characterized by districtaverage class sizes of up to 80 students. It is therefore unclear whether the results are relevant to more advanced countries. Hoxby (2000) exploits variation over time in student enrollments due to random fluctuations in the timing of births and district rules regarding maximum or minimum class sizes to identify exogenous variation in class sizes, applying this approach to elementary schools in the U.S. state of Connecticut. Unfortunately, her identification strategies require a long panel of rich data and have yet to be applied in other contexts.

In this paper, we use the international database of the Third International Mathematics and Science Study (TIMSS) and develop a new identification strategy that provides unbiased estimates of the effects of class size on student achievement in a host of school systems from all over the world. The TIMSS database provides data on representative samples of students in the two adjacent grades with the highest share of thirteen-year-old students from about 40 countries, 18 of which have data rich enough to support the implementation of our identification strategy. Our identification strategy is designed to take advantage of two unique characteristics of this database. Specifically, it exploits the fact that the TIMSS database contains information on the performance and class size of students in two adjacent grades of each school taking the same achievement test, as well as on the average class size in each grade of each school.

In a nutshell, our identification strategy uses the part of the between-grade difference in class size in a school that reflects differences in the school's average class size between the two grades to predict that part of the between-grade difference in student performance that is idiosyncratic to the school. In doing so, we exclude both betweenschool and within-school sources of student sorting. Between-school sources of student sorting are eliminated by controlling for school fixed effects, while within-school sorting is filtered out by instrumenting actual class sizes by the average class size in the 
relevant grade at each respective school. The remaining variation in class size between classes at different grades of a school is random, and presumably reflects natural fluctuations in student enrollment. We can use this random variation to identify the causal impact of class size on student performance.

The paper is organized as follows. Section II details our identification strategy, while Section III illustrates the basic intuition behind this strategy with two examples. Section IV introduces our data. In Section V, we present our estimates of causal class-size effects and compare them to naïve estimates of class-size effects. We also discuss the precision and magnitude of our estimates in greater detail, comparing them to previous estimates from the United States. Section VI concludes with some observations about the relationship between the institutional characteristics of school systems and the existence of class-size effects.

\section{The Identification Strategy}

\section{A. The Standard Method and Potential Sorting Biases}

The standard method to estimate the relationship between class size and student performance is a least-squares (LS) regression of test scores on class size, controlling for a set of family-background characteristics. Basically all of the estimates of education production functions surveyed in Hanushek $(1986,1996)$ and Krueger $(2000)$ use this method. Assuming that we use test-score data from different grades, the following education production function would be estimated:

$$
T_{i c g s}=\alpha_{1} S_{c}+C t r l_{i c g s} \beta+\gamma G_{g}+v_{c}+\varepsilon_{i c g s},
$$

where $T_{i c g s}$ is the test score of student $i$ in class $c$ at grade level $g$ in school $s, S$ is the class size, $\mathrm{Ctrl}$ is a vector of controls for student- and family-background characteristics, and $G$ is the grade level. The coefficients $\alpha_{l}, \beta$, and $\gamma$ are parameters to be estimated, $v$ is a class-specific component of the error term, and $\varepsilon$ is a studentspecific component of the error term. The following subscripts are applied throughout: $i$ is for student, $c$ is for class, $g$ is for grade level, and $s$ is for school.

While this identification method has been commonly used in the literature, it is clearly naïve to interpret the estimated parameter $\alpha_{1}$ as a causal effect of class size on 
student performance. The difficulty is that the variation in class sizes $S$ is not necessarily exogenous to the variation in test scores $T$. There are any number of plausible ways in which class size may be influenced by student performance. Parents of high-performing students may choose to live in residential districts with small class sizes to better foster their abilities. On the other hand, it might also be the case that parents of poorly performing students may choose schools with small class sizes because they feel that their children need extra attention. Schools may set up smaller remedial classes for laggards, or they may establish special enrichment classes for their most talented students. Likewise, the school system as a whole may track students of different performance levels into different kinds of schools with different average class sizes. In short, all kinds of placement mechanisms are at work in every school system, and a priori it is not even clear whether their overall effect is to place the worse- or the better-performing students in smaller classes.

In effect, every decision by parents, schools, or administrative entities that places students of different performance levels into classes of different size introduces sorting effects. These sorting effects influence the naïvely estimated relationship between class size and student performance, so that the coefficient estimate $\alpha_{l}$ is a mixture of the "true" class-size effect (the causal impact of class size on student performance) and of the consequences of sorting. The diversity and decentralized character of these decisions makes it impossible to control for the effect of sorting by including additional variables in the regression. Some kind of omitted variable bias would inevitably remain, and it may be fallacious to assume it to be of second-order magnitude. Instead, we need a strategy to identify causal effects of class sizes on student performance that bases its estimation on exclusively exogenous variation in class size.

\section{B. School Fixed Effects to Account for Between-School Sorting}

We can usefully divide the different kinds of sorting into two broad categories: sorting taking place between schools, such as residential choice or tracking by schools, and sorting taking place within schools, such as parents pressuring their children to be placed into particular classes or heads of schools assigning students to different classes. The development of the identification strategy used in this paper proceeds through two stages, each of which eliminates one of these two categories of sorting effects. 
The strategy used to eliminate the effects of between-school sorting is to control for school fixed effects (SFE). Any systematic between-school variation, stemming from any source whatsoever, is thereby removed when estimating the class-size effect. This strategy is implemented simply by including a dummy variable for each school:

$$
T_{i c g s}=\alpha_{2} S_{c}+C t r l_{i c g s} \beta+\gamma G_{g}+D_{s} \delta+v_{c}+\varepsilon_{i c g s}
$$

where $D$ is a vector of school dummies. Obviously, this identification strategy requires that our dataset contain information on more than one class from each school.

\section{Instrumental Variables to Account for Within-School Sorting}

Even having controlled for school fixed effects, however, the estimates produced by equation (2) might still be biased by sorting taking place within schools wherever there is more than one class per grade in a school. We therefore apply an instrumental variables (IV) strategy to ensure that only an exogenous part of the class-size variation is used to estimate the causal class-size effect. To be used as an instrument, a variable should be highly correlated with the endogenous explanatory variable (class size), but causally unrelated with the dependent variable (student performance). That is, the instrument should have no effect on the dependent variable apart from its indirect effect through the endogenous explanatory variable, and it should not be endogenous to the dependent variable.

The variable we use to instrument for the actual class size is the average class size at the respective grade level of the school. ${ }^{1}$ It is expected - and it is shown below - that schools' average class size in each particular grade is highly correlated with the actual class size experienced by their students in that grade. ${ }^{2}$ There is no reason to expect that the average class size would affect the performance of students in a specific class except for through its effect on the actual size of the class of the students. Furthermore, we do

1 The average grade-level class size was first applied as an instrument for actual class size in Akerhielm (1995). However, as Akerhielm did not control for school fixed effects, her estimates may still be biased by between-school sorting effects. Furthermore, Akerhielm also used the overall grade-level enrollment of a school as a second instrument in addition to average class size. However, this may be a false instrument as there might be a direct relationship between overall enrollment and student performance that is unrelated to differences in class size (cf. Angrist and Lavy 1999). Moreover, none of the coefficients on enrollment in Akerhielm's first-stage regressions are significant, suggesting that it is not a good instrument.

2 When there is only one class at a grade level in a particular school, actual and grade-average class size will be equal and the problem of within-school sorting does not exist. 
not see how student performance should have an impact on the grade-average class size, once any school fixed effect is accounted for. Given this instrument, the second stage of the two-stage least-squares (2SLS) estimation is then:

$$
T_{i c g s}=\alpha_{3} \hat{S}_{c}+C t r l_{i c g s} \beta+\gamma G_{g}+D_{s} \delta+v_{c}+\varepsilon_{i c g s},
$$

where $\hat{S}_{c}$ is the predicted value of the first-stage regression of actual class size $S_{j}$ on the average class size of the grade level in the school $A_{j}$ and the other exogenous variables:

$$
S_{s}=\phi A_{c}+C t r l_{i c g s} \beta+\gamma G_{g}+D_{s} \delta+v_{c}+\varepsilon_{i c g s} .
$$

The average difference in performance between students from the adjacent grades is controlled for by the grade-level dummy $G$, so that the remaining performance difference between the classes from the different grades is idiosyncratic to each school. This idiosyncratic variation in student performance is then related to that part of the actual class-size difference between the two grades that is due to differences in average class size between the two grades. Arguably, this remaining class-size variation is caused by random fluctuations in cohort size between two adjacent grades of a school. The coefficient estimate $\alpha_{3}$ can thus be interpreted as a true estimate of the causal impact of class size on student performance which is unbiased by within-school and between-school sorting.

Because equation (3) includes school fixed effects, and because every class size at a given grade level is instrumented by the same average class size, this IV strategy (SFEIV) requires that we have comparable information on student performance from more than one grade level in each school. As the same achievement test can only sensibly be administered to different grade levels if the students' performance levels are not too far apart, the grade levels should be adjacent. In short, our identification strategy requires a dataset with very unique characteristics. ${ }^{3}$

The class-size variation on which the estimate $\alpha_{3}$ is based, namely within-school between-grade variation, certainly is a rather specific one. Any differences in class size

\footnotetext{
3 Additionally, there should not be institutional differences in the rules determining class size between the two adjacent grades, which might introduce non-random differences in class sizes between the two grade levels. Even if there were such institutional differences, however, the inclusion of a grade dummy in all the equations ensures that the estimated class-size effects will be unbiased as long as the existence of the rule is unrelated to student performance.
} 
within one grade and any differences in class size between schools are excluded from the analysis. However, as will be discussed below, this variation has the distinct advantage of being in the relevant range of variation for potential policy initiatives in each country. The variations in class size analyzed here are generally of a magnitude that may be affordable given the budget constraints on class-size reduction, and they occur by design at the level most relevant for each country.

\section{Two Illustrative Examples}

Before actually implementing this identification strategy, we first present two graphical examples that illustrate visually the basic intuition behind our identification strategy. The specific examples we use - the mathematics performance of students in Singapore and Iceland - are chosen purely on the basis of their capacity to demonstrate the advantages of our identification strategy. While a more thorough discussion of the data is relegated to Section IV, it suffices here to point out that it comes from the Third International Mathematics and Science Study (TIMSS), which tested representative samples of seventh- and eighth-grade students in a host of countries. As a general rule, one seventh-grade class and one eighth-grade class were tested in each school. TIMSS mathematics test scores were scaled to an international mean of 500 and an international standard deviation of 100 . For these illustrative examples only, we do not use studentlevel data, but rather the average test score in each classroom. Nor do we yet control for family-background characteristics.

\section{A. Class Size and Mathematics Performance in Singapore}

In Singapore, we have 268 classes in our sample - 134 schools with one seventh-grade class and one eighth-grade class each. With an average mathematics test score of 623 , students in Singapore are the best performers of all countries participating in TIMSS. The average class size in Singapore is 33.2. Figure 1 plots the average test-score performance of students in class-size blocks of five students. Each block with five students more on average has a higher average level of performance than the previous block, indicating that students in larger classes perform better than students in smaller 
classes. ${ }^{4}$ The same counterintuitive pattern is apparent in the top panel of Figure 2, which presents a scatter plot of class-average test scores versus class size. ${ }^{5}$ Note that this positive correlation is not driven by outliers or non-linearities. Rather, the relationship between class size and student performance appears to be quite linear. Interpreting this correlation as causation would lead to the unexpected conclusion that larger classes facilitate student learning. As argued above, however, this relationship between performance and class size is likely to be spurious, reflecting the differential sorting of students between and within schools.

Looking at differences-in-differences allows us to control for the effects of betweenschool sorting. That is, for each school, we measure both the difference in average student performance between seventh and eighth grade and the difference in class size between seventh and eighth grade. This procedure removes any difference in the overall performance levels between schools (school fixed effects), leaving only within-school variation in both test scores and class sizes. The middle panel of Figure 2 plots withinschool differences in performance against within-school differences in class size. Once again we observe a statistically significant positive correlation between performance differences and class size, although the size of the positive correlation is substantially reduced. This reduction suggests that on average in Singapore, poorly performing students seem to be sorted into schools with smaller classes.

However, even the differences-in-differences picture might be distorted by various types of student sorting that occur within schools. The next step in our identification strategy accordingly attempts to eliminate any effects of within-school sorting by using only that part of the between-grade variation in actual class sizes that reflects variations in grade-average class sizes. We first regress the between-grade difference in actual class size on the between-grade difference in grade-average class size (that is, we

\footnotetext{
4 This pattern of performance steadily increasing with class size in Singapore is driven mainly by performance differences within seventh grade. Within eighth grade, the only statistically significant difference in performance between the different blocs of class sizes is that classes with more than 39 students scored higher, on average, than classes with 35-39 students. Within seventh grade, all the performance differences between consecutive blocks reported in Figure 1 are statistically significant excepting 35-39 versus 40-45 and 10-14 versus 15-19.

5 For purposes of clarity, the trend line in the top panel of Figures 2 and 3 does not control for the grade level of each class. However, trend lines controlling for grade level would look just the same in both cases.
} 
instrument actual class size by grade-average class size), and then use the predicted between-grade difference in class size for each school from this regression as the measure of between-grade difference in class size on the horizontal axis of the bottom panel of Figure 2. This scatter plot reflects the basic idea of our identification strategy: It relates that part of the between-grade difference in class size in each school that reflects differences in the average class size of the two grades to the difference in student performance between the two grades in the school. Having eliminated the effects of student sorting both between and within schools, we interpret the bottom panel of Figure 2 as a picture of the causal effect of class size on student performance. The picture suggests that class size has no causal effect on student performance whatsoever in mathematics in Singapore. Rather, weaker students seem to be consistently placed in smaller classes, both between and within schools.

\section{B. Class Size and Mathematics Performance in Iceland}

The second country we use to illustrate our identification strategy is Iceland. The mathematics sample in Iceland consists of 131 classes in 65 schools (there was one school where two seventh-grade classes were tested). The average TIMSS test score in mathematics in Iceland was 467, and the average class size 20.3. Figure 3 depicts the same three scatter plots for Iceland that were depicted in Figure 2 for Singapore.

The top panel of Figure 3 shows that class size and mathematics performance in Iceland are uncorrelated. Note that there are some extremely small classes in Iceland; however, these do not reflect unusually small schools, which were excluded from the TIMSS sample. Using differences-in-differences to exclude between-school differences in performance levels in the middle panel again reveals no obvious relationship between class size and performance. The lack of a substantial change in the slope of the trend lines between the first two panels of the figure suggests that in Iceland, unlike in Singapore, students of lower ability are not systematically sorted into schools with smaller classes. The bottom panel of Figure 3 again provides the picture most representative of our identification strategy, which excludes any sorting effects. This 
final picture reveals a negative relationship between class sizes and student performance - smaller classes seem to cause better mathematics performance in Iceland. ${ }^{6}$

Although the simple correlation between class size and student performance in Iceland initially suggests that there is no relationship between the two, this lack of correlation cannot be taken at face value. Our identification strategy reveals that smaller classes do in fact enhance students' learning in mathematics in Iceland. In this simple class-level correlation without control variables, the negative coefficient on class-size differences is statistically significant at the 10 percent level. The class-size coefficient is slightly larger than 2 (in absolute terms), implying that a class size smaller by one student elevates student performance by 2 TIMSS test-score points. That is, a class that is 5 students (or a quarter of the average class size in Iceland) smaller than another one would have performed, on average, slightly more than 10 test-score points (or 10 percent of an international standard deviation in TIMSS test scores) better as a result of the class-size effect.

\section{Examples of Individual Schools in Iceland}

The basic features of our identification strategy, and of the class-size/performance link in Iceland, can be further illuminated by looking at several cases of individual schools. The three schools, A to $\mathrm{C}$, that we discuss here are all real schools taken from the TIMSS data for Iceland. In school A, the sampled seventh-grade class has 21 students, and the sampled eighth-grade class has 25 students. The same is true for the average class sizes in seventh and eighth grade in this school, suggesting that the school may only have one class in each of these two grades. The seventh-grade class is thus smaller, both on average and actually, in school A. The average performance of the seventhgrade students sampled in school A is 462 , and in eighth grade it is 473 . That is, the tested eighth-graders in school A performed 11 test-score points better than the seventhgraders tested in school A. On average across all schools in Iceland, however, eighthgraders performed 31 points better than seventh-graders. This means that the smaller class size in seventh grade in school A might have led to a lag in performance relative

6 The result stays virtually unchanged when the two outlying observations at the right-hand side of the graph are dropped. Additionally dropping the outlying observation at the bottom of the graph, the coefficient on class size grows (in absolute terms) to -3.01 and is statistically significant at the 5 percent level. 
to eighth-graders that is smaller than the lag usually observed. It is informative to note here that a between-school evaluation in this case would have led to the opposite, counterintuitive result. The average test score of seventh-graders in Iceland is 450, and the average class size (when averaged over classes, not students) is about 14.5 in both seventh and eighth grade. Although the size of the seventh-grade class in school A is significantly above average, its performance is also above average. However, this between-school variation might be contaminated by various forms of sorting.

In school B, the tested seventh-grade class has 26 students, and the tested eighthgrade class has 19. The grade-average class sizes in school B are 25 in seventh grade and 17 in eighth grade. That is, the tested eighth grade is smaller than the tested seventh grade, and this difference seems to be caused by a smaller student cohort in eighth grade in school B. The seventh-graders scored 429 points on average, the eighth-graders 494 . The lead of the eighth-graders is thus 65 test-score points, which is substantially larger than the country-average lead of 31 points, and we would attribute the relatively better performance of the eighth-graders to their smaller class size.

In school C, the seventh-grade class actually tested was larger by 3 students than the tested eighth-grade class (24 versus 21 students). The lag in performance, however, was only 13 test-score points (as compared to the country-average lag of 31 points). As such, this would seem counterintuitive. However, the average class size in seventh grade in school $\mathrm{C}$ was 23 , while it was 24 in eighth grade. That is, the tested eighthgrade class was smaller by 3 students than the average eighth-grade class. It might be suspected that the tested eighth-grade class is one where poorer-performing students had been sorted into a smaller-than-average class, perhaps in an effort to provide them with extra attention. Therefore, the relatively small lead of tested eighth-graders in school $\mathrm{C}$ might have nothing to do with a causal class-size effect, but might be due to within-school sorting.

These illustrative examples at the country and the school level confirm that it can be highly misleading to take naïve estimates of class-size effects for causal effects. However, by applying an identification strategy that accounts for sorting effects, causal class-size effects can be distilled. The preliminary analyses presented here suggest that there does not seem to be a causal class-size effect on mathematics performance in Singapore, but that smaller classes do lead to superior mathematics performance in 
Iceland. The difference between the two results reinforces the importance of assessing the impact of class-size resources independently for different school systems.

\section{Data and Descriptive Statistics}

\section{A. Some Background on the TIMSS Database}

As indicated in Section II, the proposed identification strategy is rather demanding in its data requirements. Specifically, it requires a dataset with two features: first, performance, class-size, and student-background data from more than one grade level in each school taking the same achievement test; and second, additional information on the average grade-level class size for each grade in each school. The data collected in the Third International Mathematics and Science Study (TIMSS) for a host of countries is the only large-scale dataset we are aware of that meets these stringent requirements. ${ }^{7}$

TIMSS, conducted in 1994/95 by the International Association for the Evaluation of Educational Achievement (IEA), was the largest and most encompassing international study of student performance ever conducted, with more than 40 countries initially participating. Each of these countries administered the test to a nationally representative sample of middle school students, defined as those students enrolled in the two adjacent grades that contained the largest proportion of 13-year-old students at the time of testing (grades seven and eight in most countries). All countries endorsed the curriculum framework which was set up to ensure that the test content was appropriate for the students in both grades and reflected their current curriculum. Students were tested in a wide array of content dimensions in mathematics and science, using both free-response and multiple-choice items. In addition, extensive background information was gathered through student, teacher, and school-principal questionnaires. In the end, datasets for the middle school years were made available for 39 school systems around the world.

\footnotetext{
7 Note that not even the other recent international student achievement tests allow for an implementation of our identification strategy. In the repeat study of TIMSS conducted in 1999, data was collected for students from only one grade (eighth, but not seventh), making the between-grade assessment within each school which is necessary to implement our identification strategy impossible. In the Programme for International Student Assessment (PISA), conducted by the OECD in 2000, the target population was that of 15-year-old students, so the sampling frame did not provide for a clear sampling of two classes in two grades per school. Furthermore, the PISA school questionnaire does not provide data on grade-average class size, which would be necessary to implement our identification strategy.
} 
Student performance in mathematics and science were measured separately using the scale of international achievement scores, which have an international mean of 500 and an international standard deviation of 100. Data on the actual class size of each mathematics and science class is available in the background questionnaires completed by each teacher. Data on the school-level average class size in grades seven and eight are available from the school-principal background questionnaires. Finally, family background data is contained in the student background questionnaires. We use the international TIMSS database constructed by Wößmann (2000), which merged performance data and data from the different background questionnaires for each individual student. This database also includes imputed data for missing values of the variables contained in the background questionnaires. Complete performance data is available for all participating students.

Each country was meant to collect data for a sample of at least 150 schools. While a few countries did not reach this target, others like Canada sampled as many as 429 schools. Generally, one class per grade was selected at random within each sampled school, and all of its students tested. ${ }^{8}$ Some countries tested more than one class per grade. Schools in geographically remote regions, extremely small schools, and schools for students with special needs were excluded from the target population. Within sampled schools, disabled students who were unable to follow even the test instructions were excluded; students who merely exhibited poor academic performance or discipline problems were required to participate (Foy et al. 1996; s. a. Martin and Kelly 1998: Appendix B). The overall exclusion rate was not to exceed 10 percent of the total student population.

To be able to implement our identification strategy, we were forced to restrict the sample to those schools in which both a seventh-grade and an eighth-grade class were actually tested. Furthermore, for a school to be included, both data on the actual class size and data on the grade-average class size had to be available for both the seventhgrade and the eighth-grade class. This second criterion ensures that our class-size estimates are based on non-imputed values for our variables of interest: actual class size, instrument, and student performance. We ultimately conducted our analysis on the

8 Deviations from this general rule for the sampling of schools and students are documented in Martin and Kelly (1998: Appendix B). 
18 of the 39 countries for which data for at least 50 schools in both mathematics and science remained after applying these criteria. Appendix 1 details the specific reasons for the exclusion of each of the other TIMSS participants.

\section{B. Descriptive Statistics}

The number of students, classes, and schools per country in our mathematics and science sample are presented in the first three columns of Tables 1 and 2 . In mathematics, the number of schools ranges from 55 in Hong Kong to 168 in Canada; in science, it ranges from 50 in Hong Kong to 148 in Japan. The smallest number of students is in Iceland (1,448 in science), the largest in Japan (10,142 in mathematics). Tables 1 and 2 also present descriptive statistics of the dataset. Portugal exhibits the lowest average test scores (439 in mathematics and 453 in science), while Singapore achieves the highest (623 and 577). We use the following variables to control for student and family background: the student's sex, age, and country of birth, data on whether the student is living with both parents, and parental education and the number of books in the student's home (both categorical variables with five categories).

Appendix Tables A1 and A2 compare the sample of students included in our study to the full sample of students tested by TIMSS. The highest share of students excluded in our mathematics sample is in Iceland (55 percent), and it is Canada in our science sample (75 percent). At the opposite extreme, less than 2 percent of the tested students in either mathematics or science were excluded in Japan. The difference in the average performance between the included and the full sample of students is quite small in all the countries, except for science performance in Iceland, where the difference is 9 testscore points. There are also almost no substantial differences in the student- and familybackground data for the included and the full samples of students. The largest differences by far are that the share of female students included in the French school system of Belgium is 4.2 percentage points larger than the original share in mathematics (6.7 percentage points in science), and that the share of parents who finished university in Iceland is 5.9 percentage points smaller in our mathematics sample (5.2 percentage points in science). In the science sample, the share of parents with a university degree is also smaller in Canada (6.1 percentage points), while the share of parents with some education after secondary school is larger in Romania (6.1 percentage points). Apart 
from these relatively minor exceptions, however, the sample of students that we include in our study is very similar to the full sample of students tested in TIMSS, making us confident that the exclusion of students is unrelated to our variables of interest and thus does not introduce bias to our estimation.

Tables 3 and 4 present descriptive statistics on class size. The smallest average class size of 20.3 students per class is found in Iceland, closely followed by the two Belgian school systems (column (1)). With an average of 56.9 students per class in mathematics and 48.8 in science, Korea has the largest classes by far. The other East Asian countries also feature relatively large classes of more than 30 students. The country averages of the grade-average class size in a school (column (2)) are generally quite similar to actual class sizes, except for the fact that Korea's grade-average class size is only 50.5 students in mathematics. The amount of within-country variation in grade-average class sizes is somewhat smaller than the variance in actual class sizes. This is of course what we would expect, as outlying cases of extremely small and large tested classes are balanced out by other classes within the same grade.

Column (3) of Tables 3 and 4 reports the class-size difference between the seventhand eighth-grade classes actually tested in each school. On average, there are no sizable differences in class size between seventh and eighth grade. The only exceptions are Korea and Singapore, where on average over all schools, the eighth-grade classes have between 4.2 and 6.9 students more than seventh-grade classes. In Korea, these differences vanish once we look at the difference in the grade-average class size (column (4)). Thus, there do not seem to be institutional differences within countries in the rules governing class size between seventh and eighth grade, with the exception of Singapore. Even there, any effect of this rule on our estimates of class-size effects should be controlled for by the inclusion of a grade dummy in the estimation, as long as the rule is unrelated to student performance.

As outlined above, our estimation strategy focuses on the difference in class size between seventh and eighth grade within each school. The standard deviations reported in parentheses in the first four columns of Tables 3 and 4 demonstrate that the variation in the grade difference in class size is by and large comparable to the variation in actual class sizes in every country. That is, our estimates of class-size effects on student 
performance draw from a range of class-size variations comparable to the actual variation in each country.

The standard deviation in the between-grade difference in average class size ranges from 1.1 in Hong Kong to over 6 in Spain and Singapore, with an average over the 18 countries in our sample of 3.5 , or 13 percent of the average actual class size. In other words, our estimates of class-size effects draw on a range of variation that encompasses the range of feasible policy initiatives in most countries. Columns (5) and (6) of Tables 3 and 4 show the minimum and maximum of the difference in the average class size between seventh and eighth grade in a school for each country, providing further information on the range of variation in class sizes we are able to use.

Exceptions with low variation in class size are Hong Kong and Scotland, where there is not much variation left once between-school variations as well as within-grade variations in a school are accounted for. The standard deviation of the between-grade difference in average class size is less than 2 in these two countries, while it is larger than 2 in all other countries. The largest positive class-size difference between eighthand seventh-grade classes in a school is only 2 in Hong Kong, and the largest negative difference between eighth- and seventh-grade classes is only 3 . That is, there seems to be basically no between-grade variation in average class size within individual schools in Hong Kong and Scotland, leaving little variation in class size on which to base our estimation.

In columns (7) and (9) of Tables 3 and 4, coefficient estimates of a simple regression of actual class size on grade-average class size are reported for each country. The regression reported in column (7) has no constant. As is evident, the estimates are very close to 1 in all countries. Column (8) reports the probabilities, based on a Wald test, that these estimates can be statistically significantly distinguished from 1. Even though these coefficients are very precisely estimated, they are statistically indistinguishable from 1 in most countries. This shows that the data on actual class size, collected from teachers, are consistent with the data on grade-average class size, collected from school principals; data from the different background questionnaires therefore seem compatible. Furthermore, these estimates confirm that the sampled classes are of the same size as the average class sizes of the grades of the sampled schools. Column (9) reports coefficient estimates of the same regression of actual class size on grade-average 
class size, this time with a constant included in the regression. These estimates are all smaller than 1 (with the exception of the Canadian science sample, where the estimate is very imprecise). This confirms that grade-average class sizes are larger than actual class sizes when actual class sizes are small, and smaller than actual class sizes when actual class sizes are large. Thus, the classes actually tested in TIMSS do indeed feature unusually small and large classes, which might reflect decisions to sort students of different ability levels into especially small or large classes. This reinforces the importance of our IV strategy, which enables us to use only that part of the variation in actual class sizes that is due to variations in grade-average class sizes.

\section{Estimation Results}

Estimates of class-size effects based on the different methods advanced in Section II for the 18 countries in our sample are presented in Tables 5 to 8 . The dependent variable in the results reported in Tables 5 and 7 is the TIMSS mathematics score, while in Tables 6 and 8 it is the TIMSS science score. To facilitate comparisons of the estimates across countries we use the non-standardized TIMSS test scores, which have an international mean of 500 and an international standard deviation of 100. All reported results control for grade level as well as for the complete set of student- and family-background variables discussed in Section IV. All regressions are performed at the level of the individual student, which allows for a perfect matching of the student- and familybackground controls to the performance of each student.

In each of our estimations, attention was given to the complex data structure produced by the survey design and the multi-level nature of the explanatory variables. To achieve nationally representative student samples, TIMSS used stratified sampling within each country, which produced varying sampling probabilities for different students (Martin and Kelly 1998). Thus, all estimations are weighted by students' sampling weights in order to obtain nationally representative coefficient estimates from the stratified survey data. This ensures that the contribution of the students from each stratum in the sample to the parameter estimates is the same as would have been obtained in a complete census enumeration (DuMouchel and Duncan 1983).

Furthermore, the explanatory variable of interest in our study, class size, is measured at a different level than the dependent variable, student performance. As shown by 
Moulton (1986), such a hierarchical structure of the data requires the addition of a higher-level error component to avoid spurious results. Thus, the error terms in equations (1) to (4) have a class-specific error component $v_{c}$ in addition to the conventional student-specific error component $\varepsilon_{\text {icgs. }}$. The clustering-robust linear regression (CRLR) method delivers consistent estimates of standard errors in the presence of hierarchically structured data (cf. Deaton 1997). CRLR relaxes the usual assumption of independence of all observations and requires only that the observations be independent across classes, allowing any amount of correlation within classes. It thus lets the data determine the structure of the error components in these equations.

\section{A. Results of the WLS and SFE Methods}

Column (2) of Tables 5 and 6 reports the coefficient on class size $\alpha_{l}$ from a standard least-squares estimation as in equation (1). More than half of these weighted leastsquares (WLS) estimates in mathematics, and nearly half the estimates in science, have a statistically significant positive sign; students in larger classes apparently performed significantly better than students in smaller classes..$^{9}$ In other words, the naïve WLS estimation method leads to the counterintuitive result that students fare better in larger classes. Moreover, this result seems quite universal: It emerges in Western Europe (e.g., Belgium, France), in Eastern Europe (e.g., Czech Republic, Romania), in Australia, and in East Asia (e.g., Hong Kong, Japan). These results immediately suggest a problem with the WLS method. The only cases with statistically significant negative coefficients on class size on the basis of the WLS method are Korea in mathematics and Iceland and Scotland in science.

Results of the estimation method that takes into account school fixed effects (SFE) as in equation (2) are presented in column (4) of Tables 5 and 6. These estimates of the coefficient $\alpha_{2}$ control for any between-school differences in student ability or educational quality. The number of countries with statistically significant positive

\footnotetext{
9 These estimates confirm the results of Hanushek and Luque (2002), who estimate class-size coefficients for mathematics performance in TIMSS using ordinary least squares (OLS) and find statistically significant positive estimates in the majority of countries. Hanushek and Luque (2002) use only classroom-level rather than student-level data, and their controls for student background are inferior to the detailed data on individual students used in this paper as they do not use the student background questionnaire. Thus, although they can control for a few school-level indicators based on principals' assessments, they lack such information as parental education or the number of books in an individual student's home.
} 
coefficient estimates decreases to about half the number found with the WLS method. On the other hand, there is only one additional statistically significant negative estimate (in science). The increased prevalence of statistically insignificant results cannot be attributed to a lower degree of precision in our estimates. On average over the 18 countries, the standard deviation of the estimates actually decreases slightly from 0.628 in mathematics (0.490 in science) with the WLS method to $0.619(0.469)$ with the SFE method. There seems instead to be less evidence of any relationship between class size and student performance once between-school differences are eliminated. Still, there remain a large number of counterintuitive results, as 10 out of the total of 36 estimates exhibit a statistically significant positive sign. As discussed before, the $\alpha_{2}$ estimates may be contaminated by the effects of within-school sorting.

\section{B. First- and Second-Stage Results of the SFE-IV Method}

The final identification strategy presented in Section II was designed to eliminate any effect of between- and within-school sorting from our class-size estimates by combining school fixed effects with an instrumental variable approach (SFE-IV). The correlation between our instrument, the grade-specific average class size in the school, and the endogenous explanatory variable, actual class size, was already reported in columns (7) to (9) of Tables 3 and 4. It was shown that there is a strong and statistically highly significant correlation between actual class size and grade-average class size within all countries in both mathematics and science, with only 3 exceptions. Once controlling for a constant, the coefficient on grade-average class size was statistically insignificant in Flemish Belgium and Korea in mathematics and in Scotland in science. However, the estimates reported in Tables 3 and 4 contained no further controls as additional righthand-side variables.

Column (1) of Tables 7 and 8 reports the coefficient $\phi$ on grade-average class size of the first-stage regression of the 2SLS estimation of our SFE-IV method (equation (4) in Section II), where school fixed effects, grade level, and the whole set of student- and family-background variables are controlled for. Even after controlling for these factors, grade-average class size remains highly correlated with actual class size in nearly all cases. Exceptions with statistically insignificant estimates include the 3 cases mentioned above, the United States in mathematics, and Australia, Hong Kong, Korea, and the 
United States in science. ${ }^{10}$ In these cases, the grade-average class size does not retain any useful information as an instrument for actual class size after controlling for school fixed effects, grade level, and background characteristics. That is, our instrument in these countries is quite poor, and our preferred identification strategy cannot be properly applied. It may be that in these countries, the relevant subject (mathematics or science) is taught in special classes, created for example by breaking down or rearranging regular classes. Such a policy would explain why classes in these subjects do not appear to be of the same size as typical classes in the relevant grade.

The estimates of class-size effects $\alpha_{3}$ based on our SFE-IV method (equation (3) in Section II) are presented in column (5) of Tables 7 and 8. As explained in Section II, this method excludes any variation caused by between- and within-school sorting, so the coefficient $\alpha_{3}$ can be interpreted as an unbiased estimate of the causal effect of class size on student performance. The most notable feature of our SFE-IV results is the disappearance of the counterintuitive, statistically significant positive coefficients on class size in all but one case, namely Portugal in mathematics. We find a statistically significant negative coefficient on class size in France and Iceland in mathematics, as well as in Greece and Spain in science. In these four cases, smaller classes seem to produce superior student performance. In the vast majority of cases, however, the estimated coefficient is not statistically significantly different from zero.

In what follows, we discuss these results in greater detail. Section V.C compares the three identification methods in terms of the sign and significance level of the estimated class-size effects they produce. Section V.D comments on the precision of our SFE-IV estimates, while Section V.E gives a detailed assessment of their magnitude. In the end, it is the potential size of any class-size effect that decides whether a class-size reduction will be worth its costs. While many of our estimates are statistically indistinguishable from zero, they may offer for meaningful conclusions if they allow us to reject the existence of sizable class-size effects.

10 The coefficient estimate in the United States in science actually has a negative sign and is statistically significant at the 10 percent level. 


\section{Comparison of the Three Methods}

A comparison of the estimates of class-size effects based on the three methods is revealing. Imagine, for example, that we were to conduct a meta-analysis of our estimates similar to the meta-analyses in the surveys of class-size estimates conducted by Hanushek $(1986,1996)$ and Krueger (2000). Figure 4 depicts the distribution of the total of 36 estimates - pooling mathematics and science results - into statistically significant positive, statistically insignificant positive, statistically insignificant negative, and statistically significant negative categories for each of the three methods. Taking the WLS estimates at face value, we would have to conclude that in more than half the school systems in our sample larger classes produce better student performance. Only in 6 of the 36 cases would a (statistically significant or insignificant) negative coefficient be detected - indicating that students learn more in smaller classes. With the SFE method, we would still find a statistically significant positive coefficient in more than a quarter of the cases. Among the statistically insignificant estimates, the relative number of negative signs increases.

Using our SFE-IV identification method, we do not detect a statistically significant effect of class size on student achievement for most school systems in our sample. In four cases, however, we observe that smaller classes have led to a superior level of student performance. Only in one case do we obtain a counterintuitive statistically significant positive effect. ${ }^{11}$ The statistically insignificant estimates are rather evenly split between positive and negative results, with a slight majority negative.

\section{Precision of the SFE-IV Estimates}

The question arises whether the increasing prevalence of statistically insignificant estimates of the class-size coefficient with the SFE-IV method relative to the other methods reflects a genuine lack of a causal impact of class size on student performance, or whether it is just due to a lack of precision of the SFE-IV method. In several cases, the standard error of the estimate of $\alpha_{3}$ is extremely large. This is the case for five countries in mathematics and for three countries in science. These countries are

11 This pattern of results contrasts with Hanushek and Luque's (2002) conclusion, also based on TIMSS data, that sorting effects do not heavily influence estimates of class-size effects. Their assessment relies primarily on the use of weak proxies in an attempt to restrict their analysis to schools with only one class per grade, and it does not address the possibility of student sorting at the between-school level. 
Australia (standard error of 3.9 in mathematics and 9.5 in science), Hong Kong (7.2 and 12.8), and Scotland (6.3 and 51.9) in both subjects, plus Flemish Belgium (6.7) and the United States (69.6) in mathematics.

The lack of precision in these cases seems to be a direct consequence of the rather demanding data requirements of our identification strategy, as we can account for them in the following ways. It is obvious that the quality of the instrument as depicted by its statistical significance in the first-stage estimation is directly reflected in the precision of the estimates of the second-stage estimation. Flemish Belgium and the United States in mathematics, as well as Australia, Hong Kong, and Scotland in science, were all cases with statistically insignificant estimates in the first stage. This leaves the cases of Australia, Hong Kong, and Scotland in mathematics.

For Hong Kong and Scotland, we saw that there was basically no variation in the average class size between the two grades in a school (Section IV). The largest between-grade difference in average class size, positive or negative, observed in mathematics in any school in Hong Kong is only 3, and it is only 5 in Scotland (columns (5) and (6) of Table 3). That is, in these two countries there is simply not much of the within-school variation in grade-average class size on which our estimation strategy relies. Similarly, in Australia, Scotland, and the United States approximately 50 percent of the sampled schools exhibit no difference in average class size between the two grades, and in all three countries this is true both in mathematics and in science.

The reduced-form association between student performance and grade-average class size, reported in column (3) of Tables 7 and 8, confirms that the extremely imprecisely estimated outliers in the estimates of class-size effects are indeed consequences of weak instruments in these cases. In the reduced-form results, the extreme values vanish both among the coefficient estimates and among their standard errors. This underscores the weakness of the instrument in these cases; if there were any causal class-size effect in these cases, the instrument would be too weak to detect it.

Thus, the five cases in mathematics and three cases in science with extremely imprecise estimates of $\alpha_{3}$ can be attributed to data insufficient to implement the demanding SFE-IV identification strategy. Excluding these cases, however, the standard errors of the estimates of our identification strategy SFE-IV are only about half a testscore point larger than the standard errors of the estimates produced by the less 
demanding WLS and SFE methods. Excluding the five countries with standard errors larger than 3.9 in mathematics (Australia, Flemish Belgium, Hong Kong, Scotland, and United States), the average standard error of the remaining 13 countries is 1.022 with the SFE-IV method, compared to 0.583 with the WLS method and 0.594 with the SFE method. Similarly, excluding only the three countries with standard errors larger than 9 in science (Australia, Hong Kong, and Scotland) leaves an average standard error among the other 15 countries of 1.151 with the SFE-IV method, compared to 0.440 with the WLS method and 0.450 with the SFE method.

A standard error of approximately 1 is equal to the effect of a class-size reduction leading to a gain of 1 test-score point per student. This corresponds to a reduction in class size by 5 students leading to an increase in student performance by 5 test-score points, or only 5 percent of the international standard deviation in TIMSS test scores. In other words, a class-size reduction of 5 students that produced an increase in test scores of only 10 points, or 10 percent of a standard deviation, would be statistically significantly estimated at the 5 percent confidence level with our SFE-IV method. Apart from the 8 out of 36 cases with extremely large standard errors, therefore, the estimates produced with the SFE-IV method seem precise enough to pick up any sizable classsize effect.

\section{E. Magnitude of the Class-Size Effect}

Given the precision of the SFE-IV estimates in the remaining 28 cases, we can now assess whether there are any sizable class-size effects in educational production in these cases. As most of the previous studies that build on exogenous variations in class size by using an experimental or quasi-experimental design have been implemented for the United States, it seems sensible to compare the magnitude of our estimates of class-size effects in different countries to the previous estimates from the United States. The problem in this is that the magnitude of the existing estimates of causal class-size effects varies widely even within the United States. On the one hand, Krueger (1999) finds in his analysis of Project STAR in Tennessee a quite substantial increase in student performance due to the experimental reduction in class size. On the other hand, 
Hoxby (2000) provides quasi-experimental evidence from Connecticut that rules out the existence of even very modest causal effects of class size on student performance. ${ }^{12}$

As not even the studies on the United States come to conclusive results, we chose to assess the magnitude of our estimated effects for other school systems by comparing them to those produced by Krueger (1999), which lie at the upper bound of estimates produced so far. Krueger presents a very rough cost-benefit analysis based on these estimates suggesting that the economic benefits in terms of increased future earnings due to improved test scores caused by reducing class size fall in the same ballpark as the costs. At least in the United States, then, the benefits of smaller classes would have to be of roughly this same magnitude in order for class-size reductions to be cost effective. Krueger (1999: 530) found that the students in classes that were 7 to 8 students smaller on average than regular-sized classes performed about 0.22 standard deviations of a test score better. This means that students performed about 3 percent of a standard deviation better for every 1 student less in the class. In terms of the international TIMSS test score, this is equivalent to 3 test-score points.

None of our statistically significant point estimates of class-size effects, presented again in column (1) of Tables 9 and 10, is as large as 3 (in absolute terms). However, in three of the four cases in which we find a statistically significant negative coefficient on class size, the value of this coefficient is larger in absolute terms than 2.4. These are France and Iceland in mathematics and Greece in science. That is, in three out of the 28 reasonably precisely estimated cases we do find point estimates that are not too distant from the order of magnitude presented by Krueger.

As most of our class-size estimates are statistically insignificantly different from zero, we next consider whether we can reject with reasonable confidence an effect of the magnitude of Krueger's estimates. Columns (3) and (4) of Tables 9 and 10 present results of Wald tests that test whether our estimated coefficients are statistically significantly different from $-3 .{ }^{13}$ For eight countries in mathematics, and also for eight

\footnotetext{
12 Angrist and Lavy's (1999) estimates for Israel lie somewhere in between these two extremes.

13 While -3 would be the order of magnitude of Krueger's (1999) estimates in terms of standard deviations of the international test score (which has a standard deviation of 100), the standard deviations of the test scores within each country vary around 100 (see column (4) of Tables 1 and 2). These withincountry standard deviations of test scores range from 63.6 (in Portugal in mathematics, which is an outlier at the lower bound) to 108.0 (in Korea in mathematics). On average across the countries in our sample, the within-country standard deviation is slightly less than 100 . To estimate the magnitude of the
} 
countries in science, the tests reject a class-size effect of that order of magnitude at the 1 percent confidence level. In another three cases, such an effect is rejected at the 5 percent confidence level, and in another two cases at the 10 percent level. Thus, in 16 to 21 (depending on the degree of confidence) of the 28 rather precisely estimated classsize effects, we can reject a class-size effect of the order of magnitude of Krueger's (1999) estimates. This is not to say that we can reject any class-size effect of any order of magnitude whatsoever in these cases. It only shows that we can be rather confident that the causal effect of class size on student performance is not as large as the one estimated by Krueger for the Project STAR.

To assess whether even smaller class-size effects can be rejected for specific school systems, columns (5) and (6) of Tables 9 and 10 test whether we can reject that a class smaller by one student leads to an improvement of student performance by only a single TIMSS test-score point (equivalent to 1 percent of an international standard deviation). We can reject even such a small impact in three cases at the 1 percent level, and in a total of eight cases at the 10 percent level. In many cases, therefore, our identification strategy has considerable power to identify the existence of class-size effects.

In sum, we can split our total of 36 estimates of class-size effects from different school systems into four (slightly overlapping) broad categories: First, a group of four cases in which we find a statistically significant beneficial effect from smaller classes (France and Iceland in mathematics, Greece and Spain in science); second, eight cases where we can reject any sizable class-size effect with reasonable confidence (Japan and Singapore in both subjects, plus French Belgium, Canada, and Portugal in mathematics and Romania in science); third, another thirteen cases where we can reject class-size effects of the order of magnitude reported by Krueger (1999) with reasonable confidence (Flemish Belgium, Czech Republic, Korea, Slovenia, and Spain in both

class-size effects in terms of the standard deviation of test scores within each country, we also did the Wald tests in terms of -0.03 of a within-country standard deviation. This did not introduce any substantive changes to the results presented in columns (3) and (4) of Tables 9 and 10. Thus, we chose to present the tests relative to the same value of -3 in each country in order to maintain direct comparability across countries, which is feasible because the test scores have been scaled in the same way for all countries. 
mathematics and science, plus French Belgium, France, and Portugal in science); ${ }^{14}$ and fourth, a group of twelve cases where we cannot say any of these things about the classsize effect with a reasonable degree of confidence on the basis of our identification strategy (the eight cases with extremely imprecise estimates referred to before except for Flemish Belgium, plus Greece and Romania in mathematics and Canada, Iceland, and the United States in science). These results confirm that the question of whether there are sizable class-size effects in educational production is one that has to be answered separately for each school system. In Appendix 2, we show that our results on class-size effects are robust against several alternative specifications of the estimated relationship and against several peculiarities of the dataset.

\section{F. Interpretation of the Results}

When interpreting the results, it should be noted that there are many aspects of the level and quality of educational resources that may influence student performance, of which class size is only one. These other classroom inputs, however, are also likely to be endogenous. Lacking suitable instruments for these variables, we were forced to restrict our analysis to the effects of class size. To the extent that they are correlated with gradelevel average class sizes, any class size effects we identify could actually be attributable to these other factors. Therefore, our estimates are most precisely interpreted as the effects on student achievement of class size and all other resource inputs with which it is associated (cf. Boozer and Rouse 2001). If smaller classes are also more likely to receive more of other resources, our results may overstate the effect of class size on achievement.

Another issue to be addressed is our use of level scores as opposed to gain scores as our measure of student achievement. Because students in the TIMSS sample were only tested at a single point in time, our data do not support the estimation of value-added models of educational production. Level formulations of the kind we use instead essentially rely on the similarity in the size of students' classes over the course of their recent careers. To the extent that this assumption is violated, our estimated class-size effects will be biased towards zero. Confidence in the validity of this assumption for our

14 Note that the science estimate in Spain belongs to both the first and the third group, as it is estimated precisely enough to reject both that it is equal to zero and that it is equal to -3 with reasonable confidence. 
purposes, however, is increased by the fact that our identification strategy is explicitly designed to identify only those variations in class size caused by natural differences in student enrollment between adjacent grades in a school, which should be relatively constant over time. Moreover, the TIMSS exam was itself designed to test concepts in mathematics and science covered during the middle school years, further minimizing the potential bias resulting from this form of measurement error in our explanatory variable. In our specific case, therefore, the use of level scores seems quite plausible, and may even be superior to the use of value-added measures given the latter's greater unreliability (Kane and Staiger 2001).

Finally, in addition to estimating the causal effect of class size on student performance, our identification strategy allows us to quantify the extent to which students' levels of performance affect the relative size of the class in which they are taught. The large differences in the estimated coefficients on class size between our three different methods of estimation (see Tables 5 to 8 ) suggest that there is substantial sorting of students according to achievement levels in most of the school systems we analyze. West and Wößmann (2002) show that the nature (within or between schools), direction, and magnitude of the sorting effects in the different school systems can be linked to such likely sources of student sorting as student and family mobility, distribution of responsibility for the placement of students and classes, academic selectivity of schools, and availability of remedial or enrichment teaching, giving additional confidence in the plausibility and importance of our identification strategy.

\section{Conclusion: Where to Look for Class-Size Effects}

Are there sizable class-size effects in educational production? Our results suggest that the answer to this question depends on which school system you are looking at. It is possible to boil down the pattern of our 36 class-size estimates to a basic picture for the 18 countries, ignoring differences between the two subjects, without doing too much harm to the detailed findings presented above. In four countries - Australia, Hong Kong, Scotland, and the United States - our identification strategy leads to extremely imprecise estimates that do not allow for any confident assertion about class-size effects. In two countries - Greece and Iceland - there seem to be non-trivial beneficial 
effects of reduced class sizes. ${ }^{15}$ France is the only country where there seem to be noteworthy differences between mathematics and science teaching: While there is a statistically significant and sizable class-size effect in mathematics, a class-size effect of comparable magnitude can be ruled out in science. The nine school systems for which we can rule out large-scale class-size effects in both mathematics and science are the two Belgian systems, Canada, the Czech Republic, Korea, Portugal, Romania, Slovenia, and Spain. ${ }^{16}$ Finally, we can rule out any noteworthy causal effect of class size on student performance in two countries, Japan and Singapore.

In short, class-size effects estimated in one school system cannot be interpreted as a general finding for all school systems. In the majority of countries in our sample (11 out of 18), we can be quite confident that the effect of class size on student performance is not as large as the one Krueger (1999) found for the Project STAR. Given that in Krueger's (1999) own analysis of class-size reductions, the benefits only marginally outweigh the costs, this raises considerable doubts about the desirability of class-size reductions as a policy intervention in most of the school systems we examine. However, the results for individual countries are much more diverse. While at one extreme, Greece and Iceland do seem to show sizable class-size effects, there seem to be no class-size effects whatsoever in Japan and Singapore. In these two school systems, our estimates resemble Hoxby's (2000: 1280) "rather precisely estimated zeros".

The existence of class-size effects in Greece and Iceland, and their total absence in Japan and Singapore, raises the question of why class-size effects exist in some school systems, but not in others. The answer to this question should indicate to policymakers when class-size reductions are most likely to be effective. One might expect the existence of class-size effects to be related to such characteristics of a country as its level of development or its overall level of resources. However, columns (1), (3), and (7) of Table 11 demonstrate that there is no clear pattern in countries' GDP per capita or average class size that distinguishes countries where substantial class-size effects do

15 This assertion rests on the statistically significant sizable estimates for Greece in science and for Iceland in mathematics. The estimates for Greece in mathematics and for Iceland in science are less clearcut, but cannot rule out a sizable effect. Actually, the mathematics estimate in Greece is statistically significant at a confidence level of 13 percent, and the reduced-form estimate is statistically significant at a confidence level of 8 percent.

16 The rejection of a class-size effect of the Krueger magnitude for Canada in science and for Romania in mathematics is statistically significant at the 15 percent level only. 
exist (mainly Greece and Iceland) from those where no class-size effect exists (Japan and Singapore), or from the larger group of 9 school systems where large class-size effects can be ruled out ("no-large-CSE"). If the main influence were diminishing returns to resource inputs, one would expect the countries with notable class-size effects to be those with a lower GDP per capita and with larger class sizes. While Greece's GDP per capita is slightly below the mean of the countries where we rule out large class-size effects, Iceland's is above it; and while class sizes in Greece are similar to the mean of the no-large-CSE sample, in Iceland they are substantially lower. Thus, the existence of class-size effects does not seem to be driven by diminishing returns. ${ }^{17}$

Additionally, the countries with significant class-size effects perform below average in terms of overall achievement on the TIMSS tests (column (5) of Table 11), while the countries where even small effects are ruled out perform above average. That is, the significant class-size effects in Greece and Iceland do not suggest that these are especially "effective" systems. Quite to the contrary, they achieve much lower performance levels than Japan and Singapore despite much smaller classes. The significant class-size effects in Greece and Iceland simply imply that class-size reductions would work to raise student performance within their current institutional environments, which as a whole are rather ineffective.

To understand the existence of class-size effects (and the lack thereof), we have to turn to other characteristics of the different school systems. Columns (8) to (11) of Table 11 suggest that the overall level of educational spending is relatively low in Greece and Iceland. Columns (8) and (9) take data from Lee and Barro (2001) for 1990 (their latest available year), while columns (10) and (11) have data from the OECD for 1994. As each of these datasets is available for a different sample of countries, we present both. All these indicators suggest that, both in absolute terms and relative to the countries' GDP per capita, educational expenditures per student in Greece and Iceland are substantially below the average of the subset of countries without class-size effects.

Given that class sizes in these countries are equal to (Greece) or below (Iceland) the mean class size of the countries without sizable class-size effects, these expenditure data suggest that Greece and Iceland spend rather little per employed teacher. This is

17 This confirms previous findings based on standard OLS estimates of class-size coefficients (Hanushek and Luque 2002). 
indeed reflected in the available data on teacher salaries. Columns (12) to (16) present data on teacher salaries in the different countries. Lee and Barro's (2001) teacher-salary data (columns (12) and (13)) are available only for primary-school teachers in 1990, while the OECD data (columns (14) to (16)) refer to teachers in lower secondary education in 1994. Teacher salaries in Greece and Iceland are below the mean of the nolarge-CSE countries, both in absolute terms, in terms of salary per teaching hour, and relative to the country's GDP per capita, which might be viewed as a proxy for the overall salary level in a country and thus as the opportunity cost of becoming a teacher. Conversely, teacher salaries seem to be above average in Japan and Singapore.

A low average salary level for teachers probably means that a country is drawing its teaching population from a relatively low level of the overall capability distribution of all employees in this country. If this is the case, the different countries seem to have chosen different points on the quantity-quality tradeoff with respect to teachers: Greece and Iceland have relatively many but poorly-paid teachers, while Japan and Singapore have relatively few but well-paid teachers.

The assumption that paying teachers less would lead to a lower average level of capability in the teacher population also seems to be borne out by the available data on teacher quality. In Greece, the highest level of education reached by the vast majority of teachers is the equivalent of a BA without any teacher training (columns (17) to (22) of Table 11), based on the sample of teachers of the TIMSS students. In Iceland, about a third of the teacher population does not even have a proper degree of secondary education, but only some basic teacher training. In both countries, the share of teachers with the equivalent of an MA or Ph.D. is very small, at about 2 to 3 percent. Meanwhile, in the sample of countries without large class-size effects, more than 60 percent of the teachers received more education than a BA without additional training, and nearly 20 percent have an MA degree. Judging solely from teachers' educational levels, therefore, Greece and Iceland appear to have a population of teachers that is less capable on average than the population of teachers in the 11 countries where we can reject the existence of large class-size effects.

Thus, the evidence on class-size effects presented in this paper suggests the interpretation that capable teachers are able to promote student learning equally well regardless of class size (at least within the range of variation that occurs naturally 
between grades). In other words, they are capable enough to teach well in large classes. Less capable teachers, however, while perhaps doing reasonably well when faced with smaller classes, do not seem to be up to the job of teaching large classes. This interpretation is corroborated by the responses given by teachers sampled in TIMSS when asked to what extent their teaching was limited by a high student/teacher ratio in their classroom. While 48 percent of teachers in Greece and 42 percent in Iceland reported that their teaching was limited "a great deal" by a high student/teacher ratio (column (23) of Table 11), the percentage of teachers who gave this response averaged only 22 percent across those countries with no large class-size effects, and it was similarly low in Japan and Singapore. Given that actual class sizes in Greece and Iceland are, on average, smaller than those in Japan, Singapore, and the group average of countries without substantial class-size effects, this response pattern is suggestive both of differences in the quality of teachers in the two groups of countries and of the plausibility of the link between these differences and the existence of class-size effects.

The explanation we propose jointly explains why class-size effects exist in some countries but not in others, and why the countries where sizable class-size effects do exist are those with a poor overall performance level: Greece and Iceland exhibit classsize effects and poor overall performance because they have a population of relatively less capable teachers, while Japan and Singapore (and, to a lesser extent, the other countries for which large class-size effects are ruled out) exhibit no class-size effects but high overall performance because they have a population of relatively capable teachers. An apparent implication of our research, therefore, is that it may be better policy to devote the limited resources available for education to employing more capable teachers rather than to reducing class sizes - moving more to the quality side of the quantity-quality tradeoff in the hiring of teachers. The merits of this admittedly speculative conclusion seem a promising topic for future research. 


\section{References}

Akerhielm, Karen, “Does Class Size Matter?” Economics of Education Review 14 (June 1995), 229-241.

Angrist, Joshua D., and Victor Lavy, “Using Maimonides' Rule to Estimate the Effect of Class Size on Scholastic Achievement," Quarterly Journal of Economics 114 (May 1999), 533-575.

Boozer, Michael, and Cecilia Rouse, "Intraschool Variation in Class Size: Patterns and Implications," Journal of Urban Economics 50 (July 2001), 163-189.

Case, Anne, and Angus Deaton, "School Inputs and Educational Outcomes in South Africa," Quarterly Journal of Economics 114 (August 1999), 1047-1084.

Deaton, Angus, The Analysis of Household Surveys: A Microeconometric Approach to Development Policy (Baltimore: The Johns Hopkins University Press, 1997).

DuMouchel, William H., and Greg J. Duncan, "Using Sample Survey Weights in Multiple Regression Analyses of Stratified Samples," Journal of the American Statistical Association 78 (September 1983), 535-543.

Foy, Pierre, Keith Rust, and Andreas Schleicher, "Sample Design," in Michael O. Martin, and Dana L. Kelly (eds.), TIMSS Technical Report Volume I: Design and Development (Chestnut Hill, MA: Boston College, 1996).

Hanushek, Eric A., "The Economics of Schooling: Production and Efficiency in Public Schools," Journal of Economic Literature 24 (September 1986), 1141-1177.

Hanushek, Eric A., "School Resources and Student Performance," in Gary Burtless (ed.), Does Money Matter? The Effect of School Resources on Student Achievement and Adult Success (Washington, DC: The Brookings Institution, 1996).

Hanushek, Eric A., "Some Findings from an Independent Investigation of the Tennessee STAR Experiment and from Other Investigations of Class Size Effects," Educational Evaluation and Policy Analysis 21 (Summer 1999), 143-163.

Hanushek, Eric A., and Javier A. Luque, "Efficiency and Equity in Schools Around the World," forthcoming in Economics of Education Review (2002). 
Hoxby, Caroline M., "The Effects of Class Size on Student Achievement: New Evidence from Population Variation," Quarterly Journal of Economics 115 (November 2000), 1239-1285.

Kane, Thomas J., and Douglas O. Staiger, "Improving School Accountability Measures," NBER Working Paper 8156, National Bureau of Economic Research (March 2001).

Krueger, Alan B., "Experimental Estimates of Education Production Functions," Quarterly Journal of Economics 114 (May 1999), 497-532.

Krueger, Alan B., "Economic Considerations and Class Size," Working Paper 447, Princeton University, Industrial Relations Section (September 2000).

Krueger, Alan B., and Diane M. Whitmore, "The Effect of Attending a Small Class in the Early Grades on College-Test Taking and Middle School Test Results: Evidence from Project STAR,” Economic Journal 111 (January 2001), 1-28.

Lee, Jong-Wha, and Robert J. Barro, "Schooling Quality in a Cross-Section of Countries," Economica 68 (November 2001), 465-488.

Martin, Michael O., and Dana L. Kelly (eds.), TIMSS Technical Report Volume II: Implementation and Analysis, Primary and Middle School Years (Chestnut Hill, MA: Boston College, 1998).

Moulton, Brent R., "Random Group Effects and the Precision of Regression Estimates," Journal of Econometrics 32 (August 1986), 385-397.

OECD, Education at a Glance: OECD Indicators (Paris: Organisation for Economic Co-operation and Development, 1996-2001).

West, Martin R., and Ludger Wößmann, "Regressive and Compensatory Education Systems: Sorting Between and Within Schools Around the World," Mimeo, Harvard University and Kiel Institute for World Economics (March 2002).

World Bank, World Development Indicators CD-Rom (Washington, DC: International Bank for Reconstruction and Development, 2000). 
Wößmann, Ludger, "Schooling Resources, Educational Institutions, and Student Performance: The International Evidence," Working Paper 983, Kiel Institute for World Economics (December 2000). 


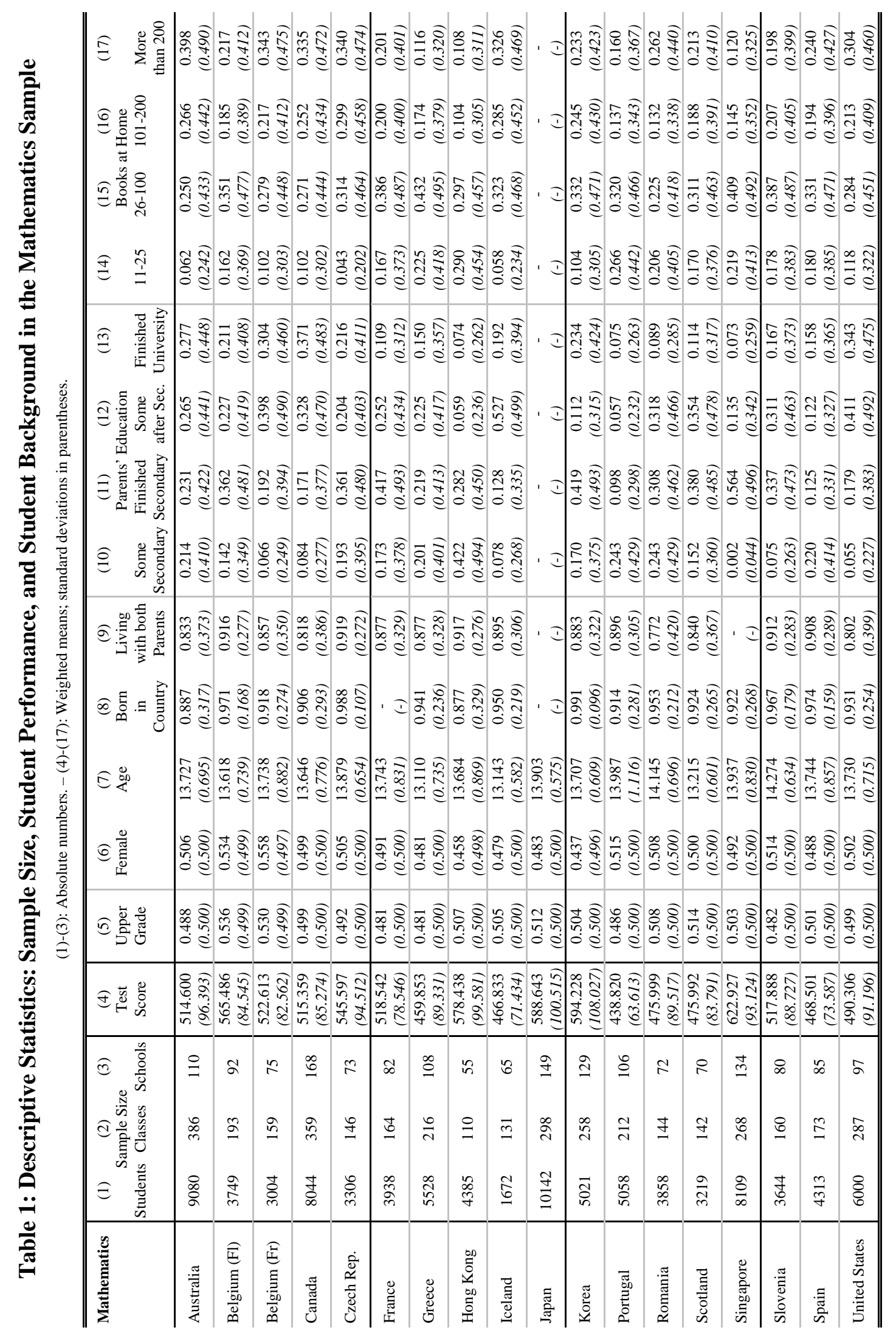




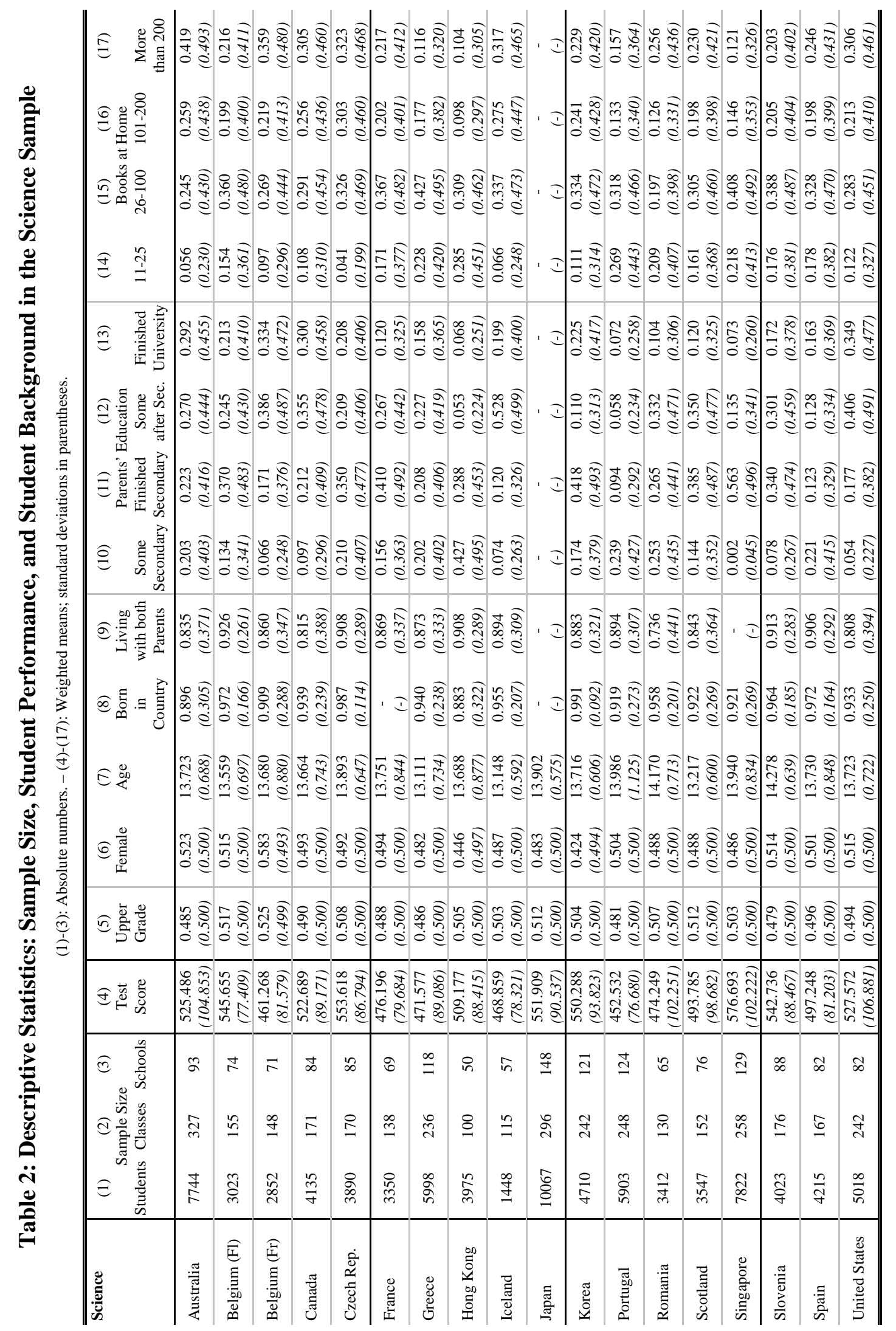




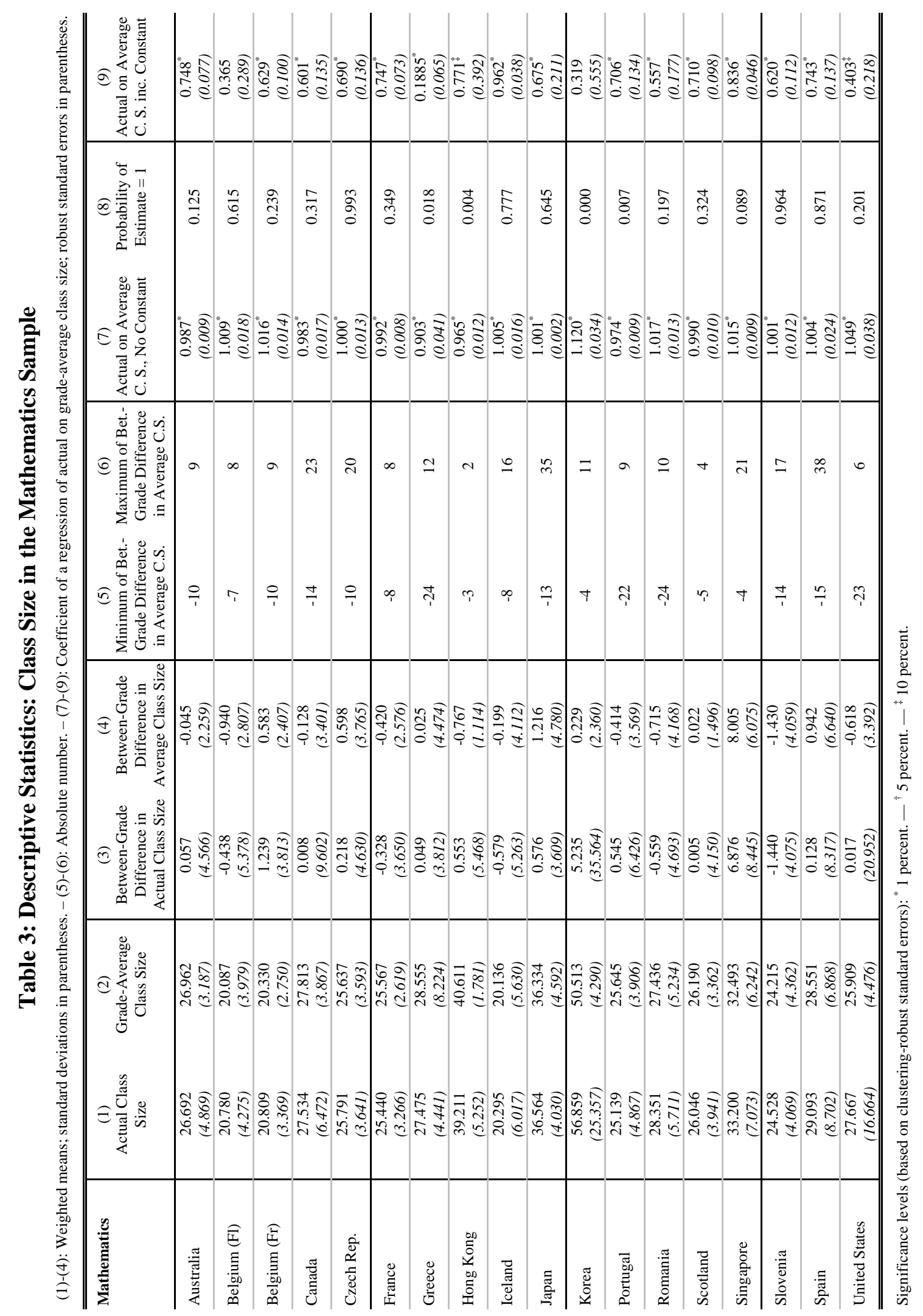




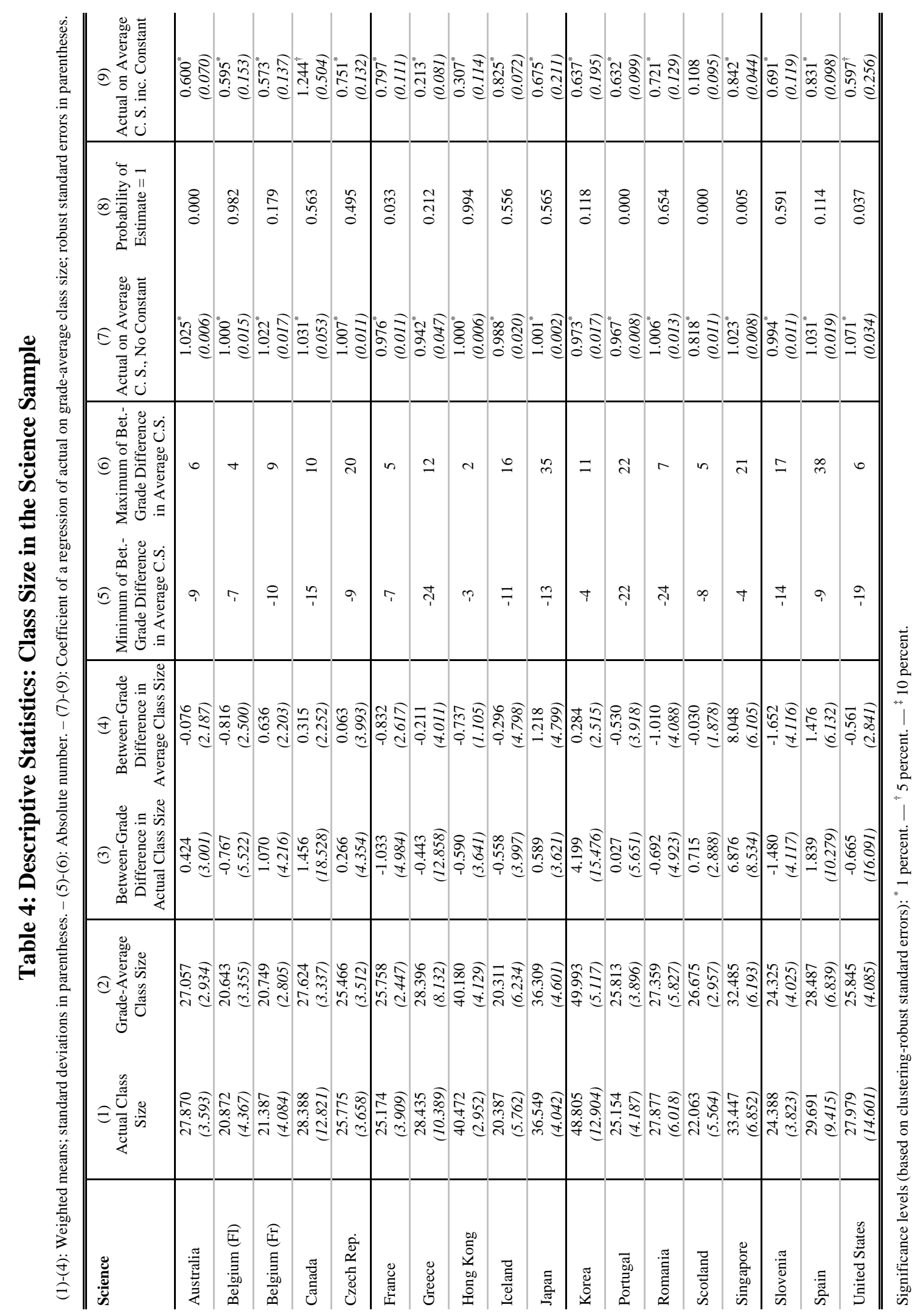




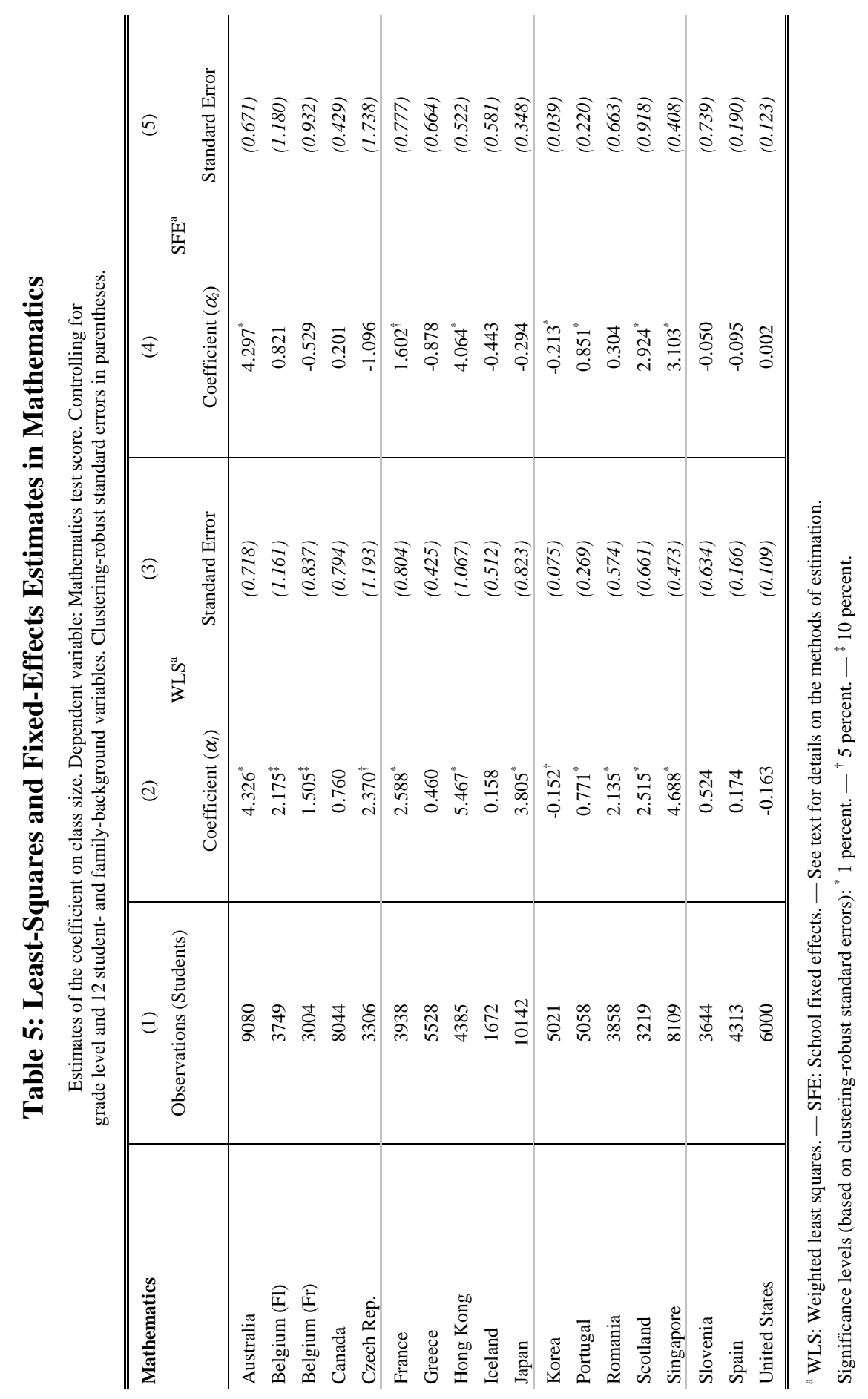




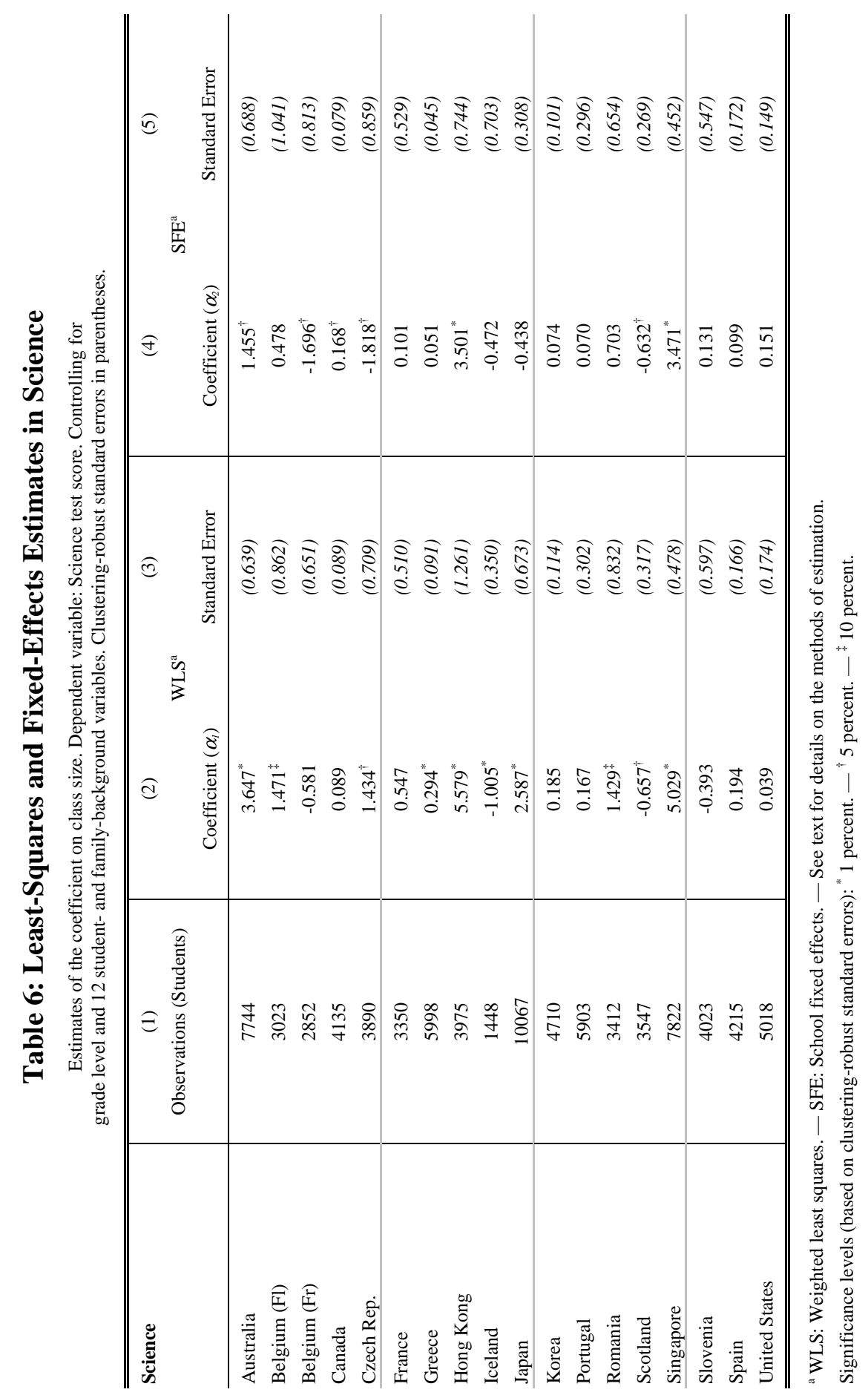




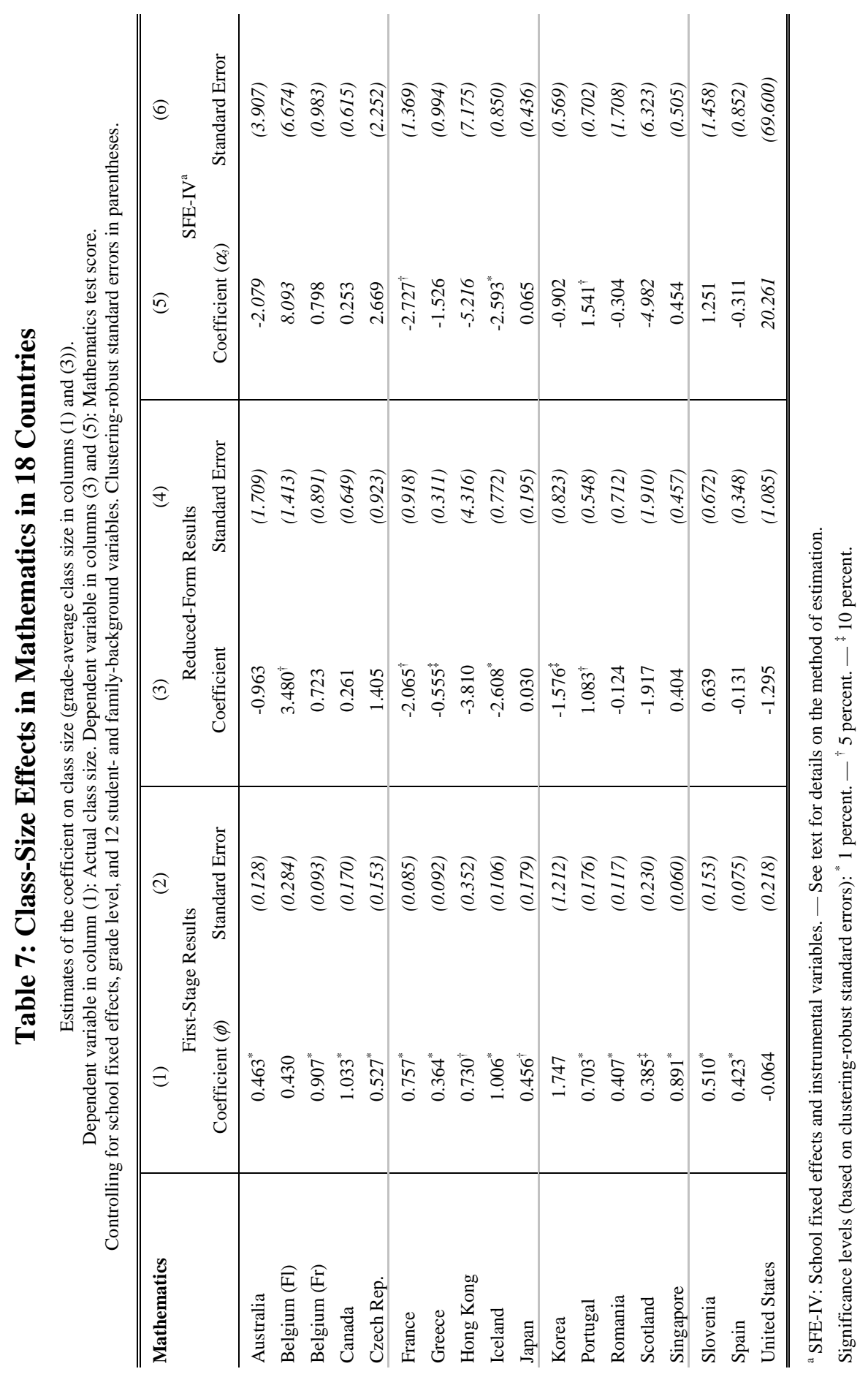




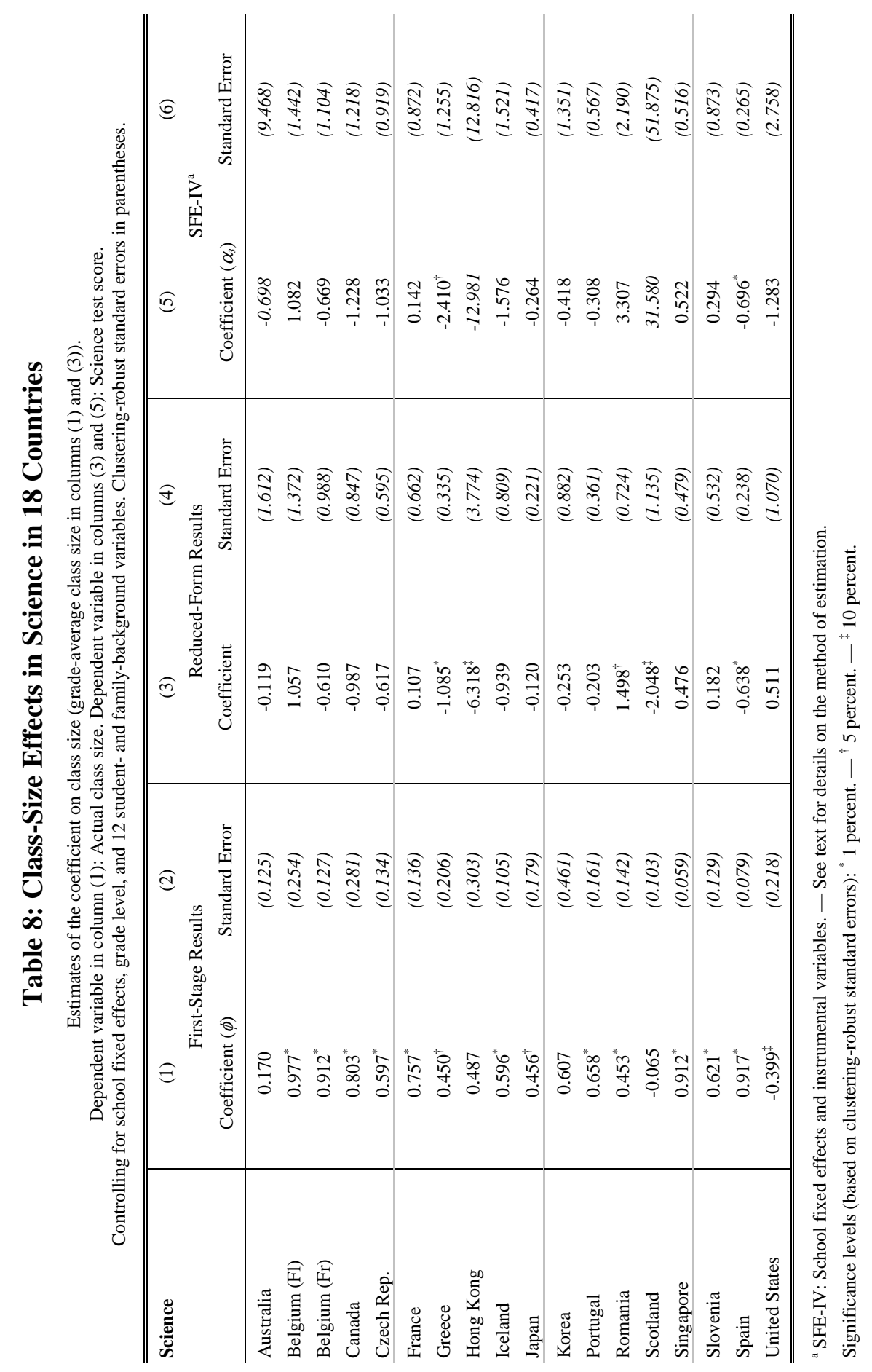




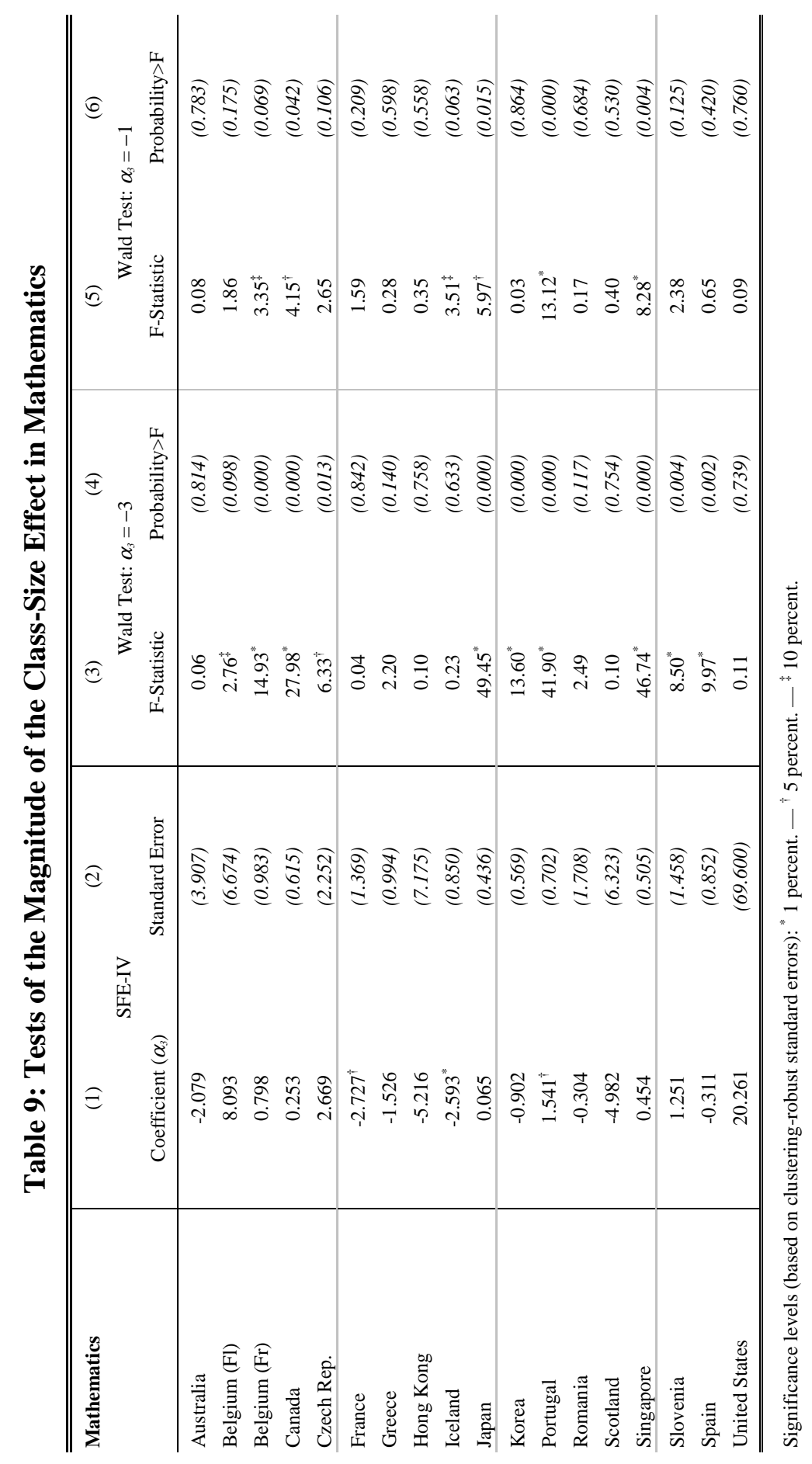




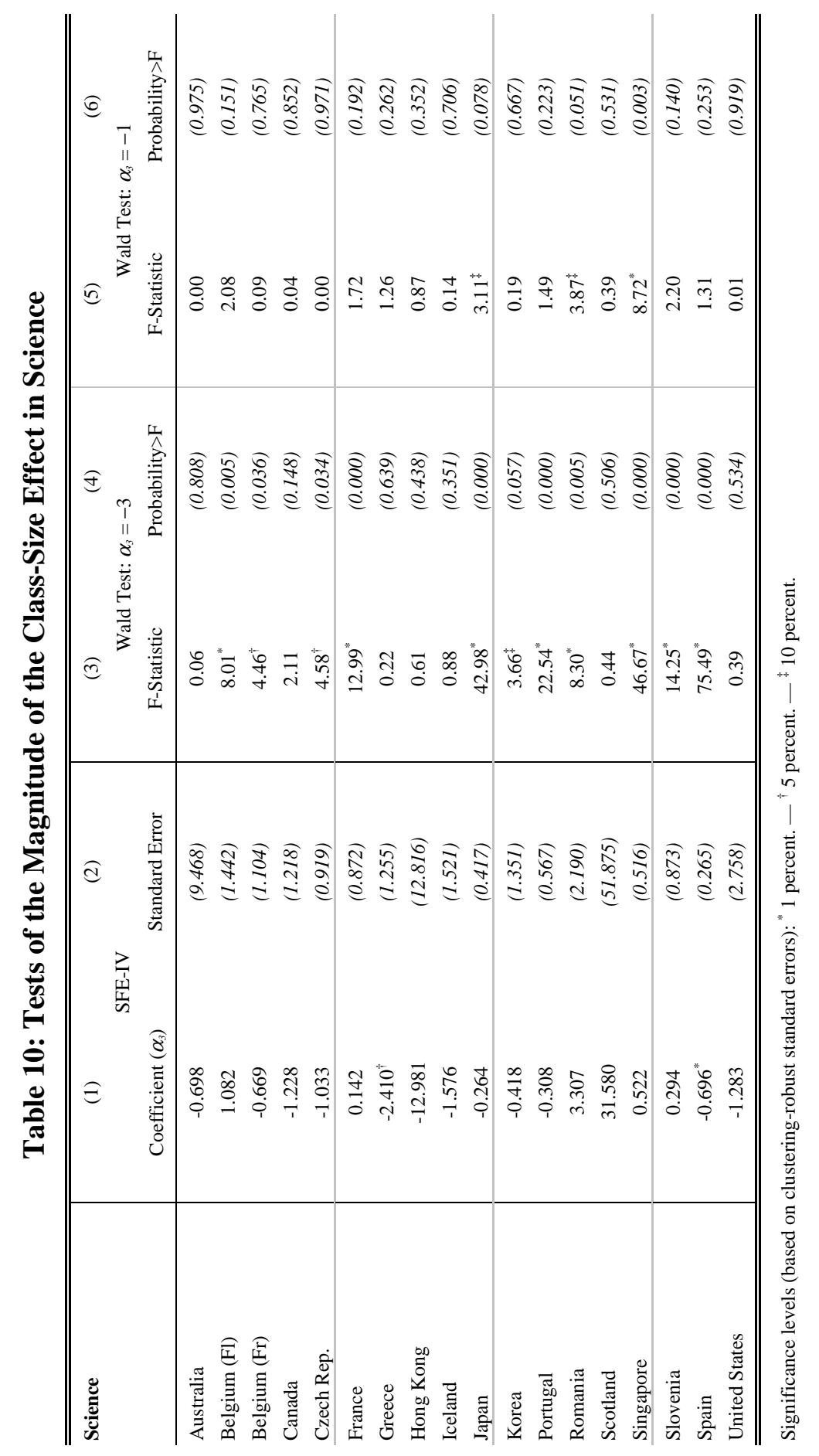




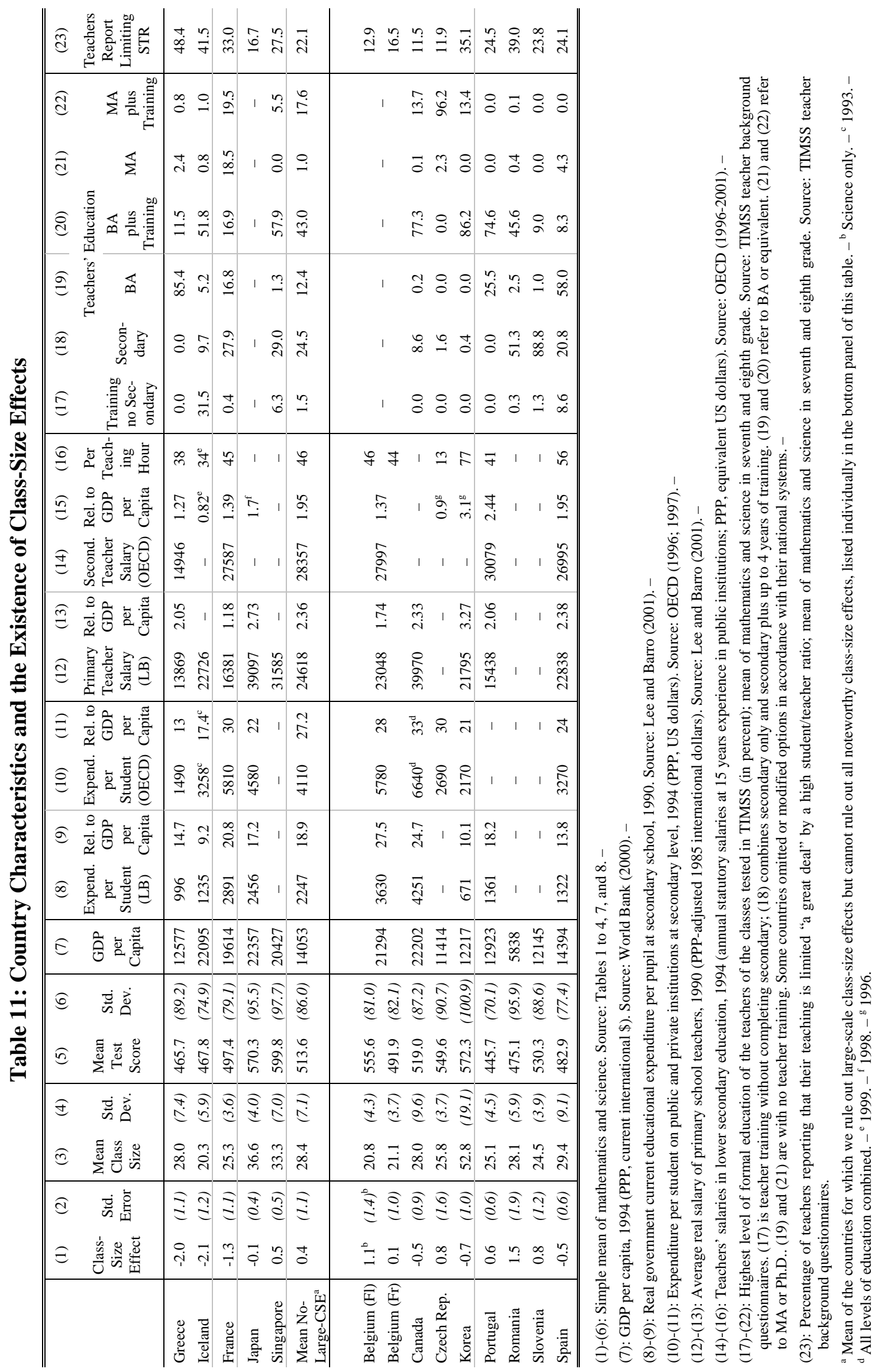


Figure 1: Mathematics Performance by Class-Size Blocs in Singapore

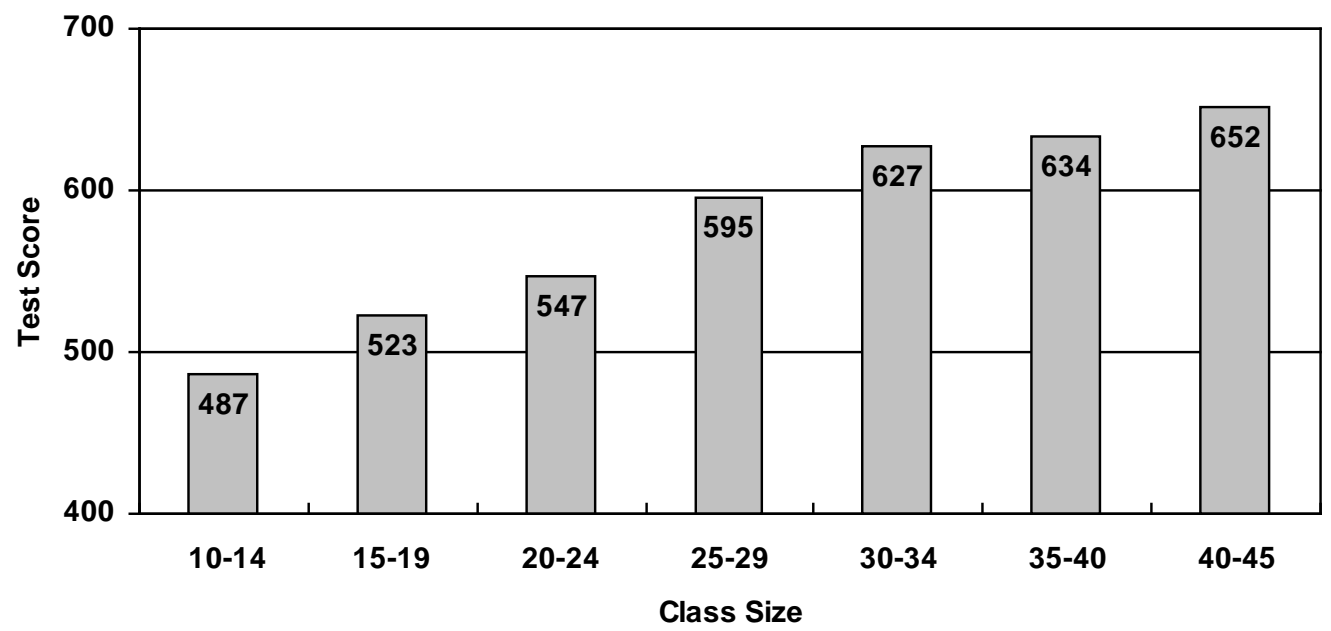


Figure 2: Class Size and Mathematics Performance in Singapore
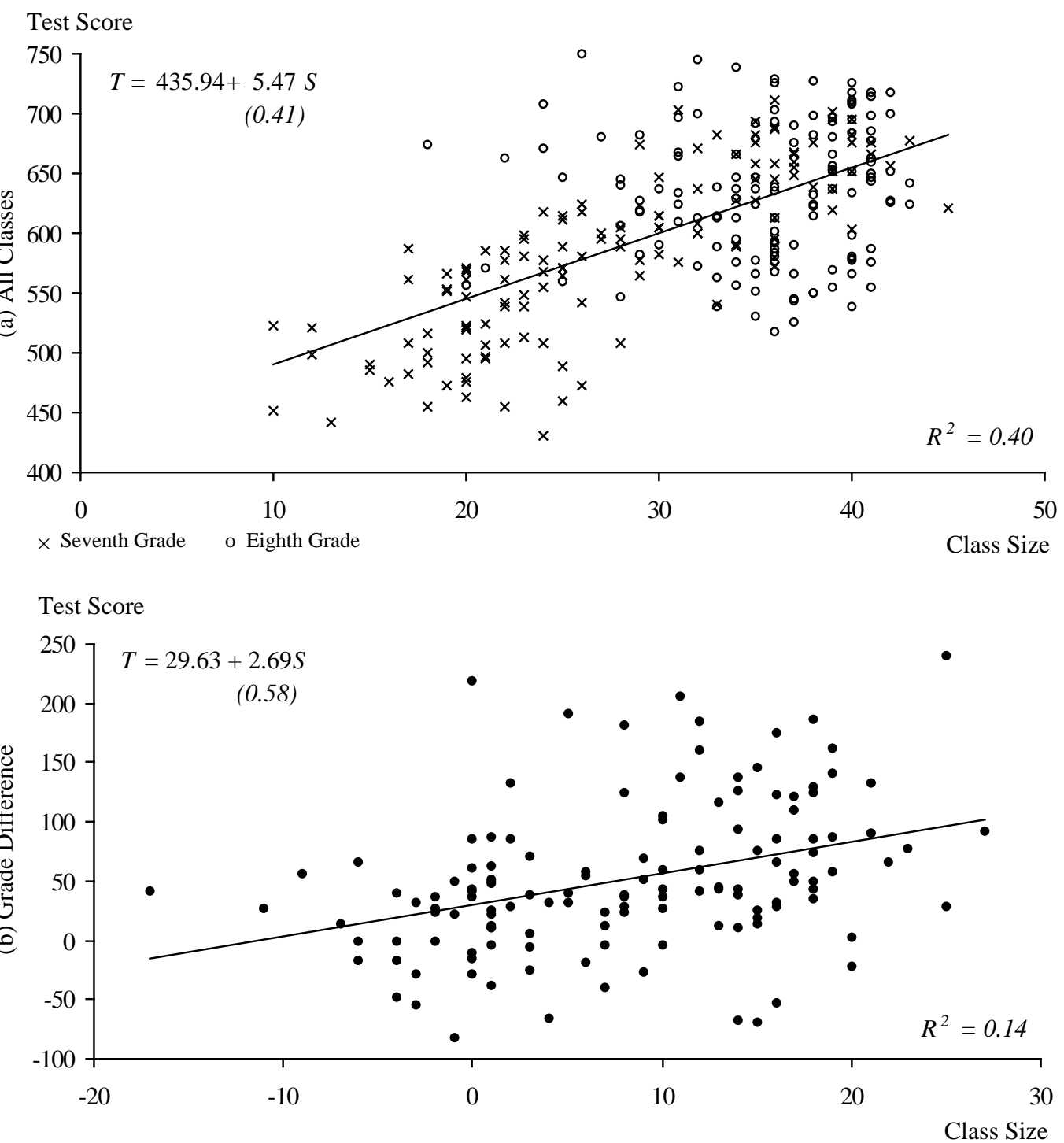

Test Score

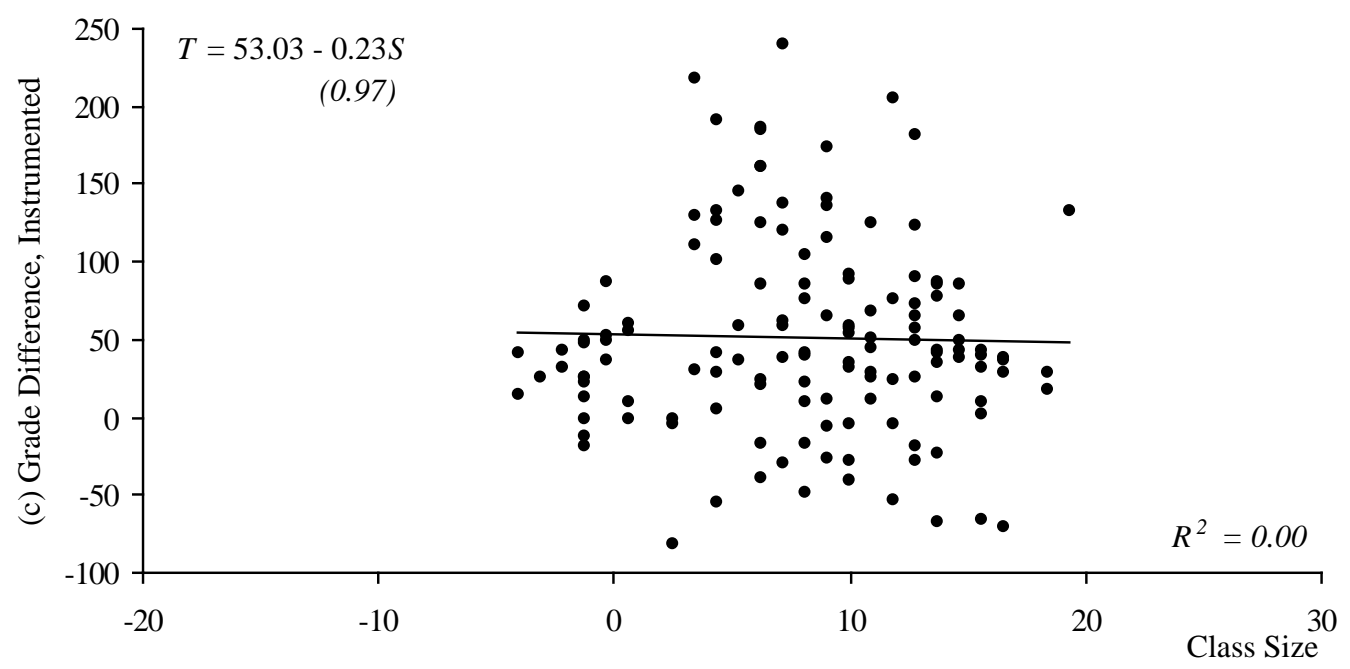


Figure 3: Class Size and Mathematics Performance in Iceland
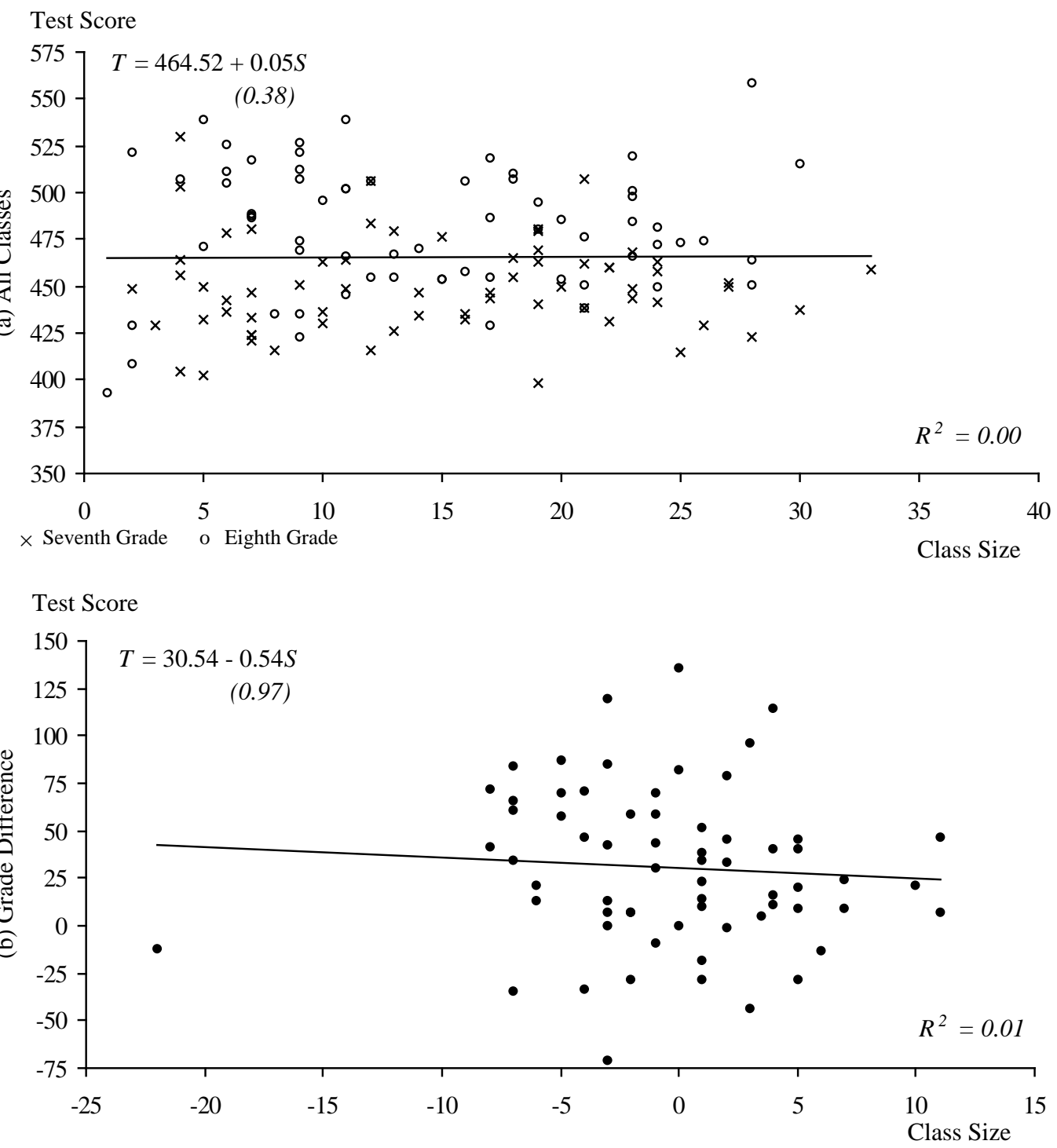

Test Score

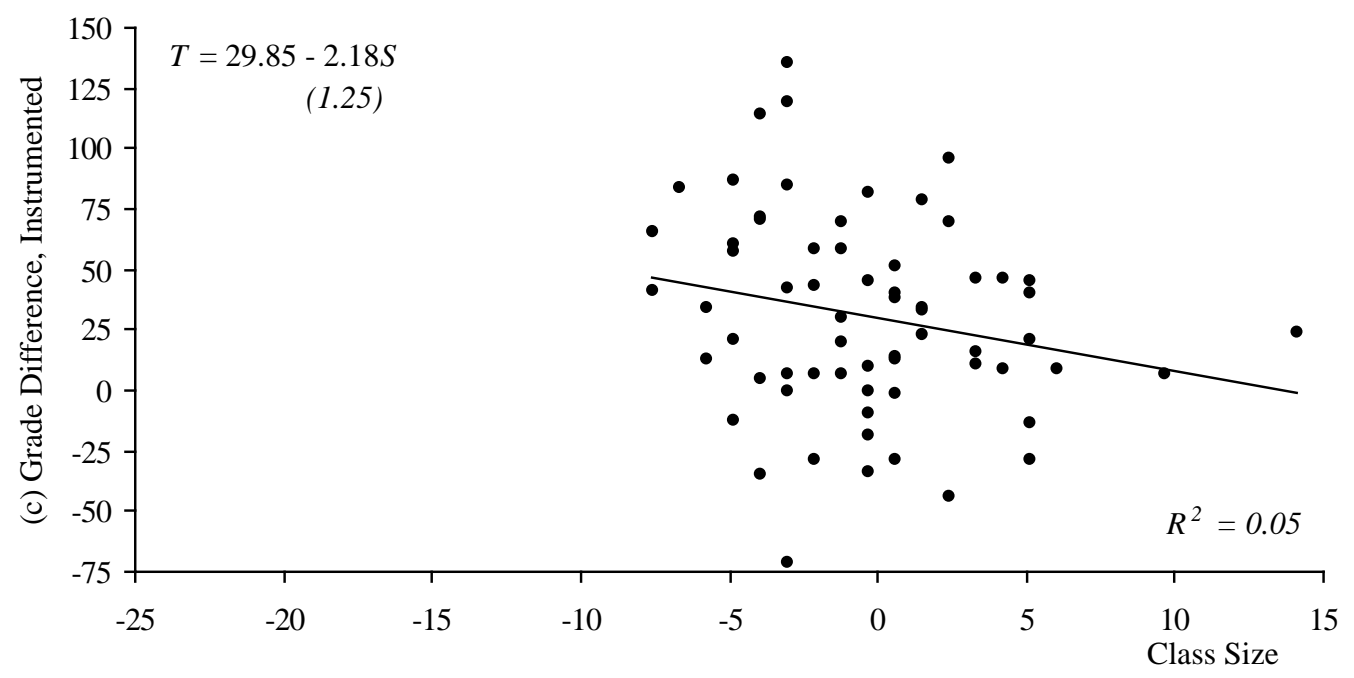


Figure 4: The Coefficient on Class Size ${ }^{a}$

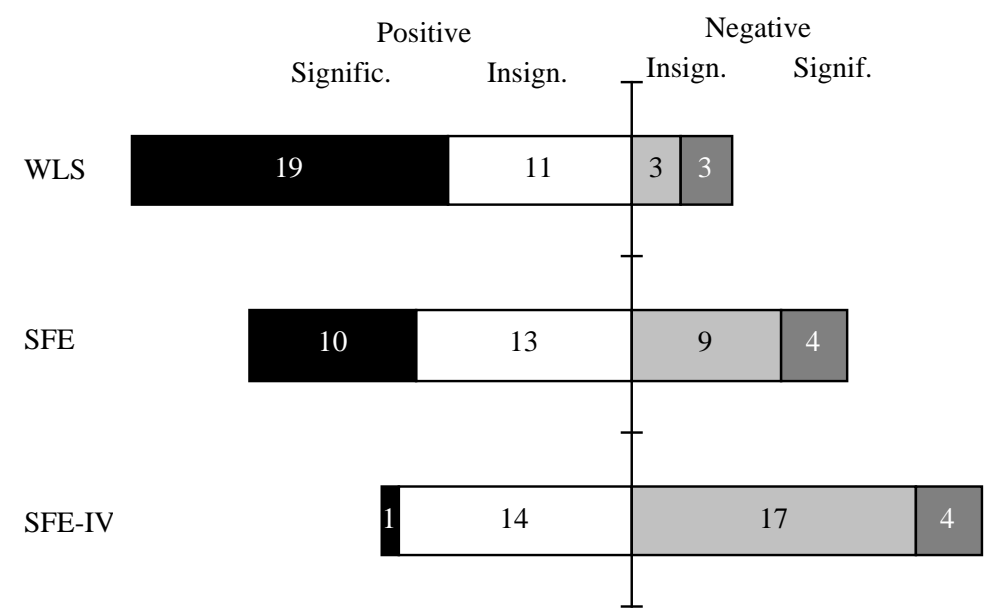

a Number of cases showing a statistically significant positive (black), a statistically insignificant positive (white), a statistically insignificant negative (light gray), and a statistically significant negative (dark gray) coefficient, respectively. — WLS: Weighted least squares. - SFE: School fixed effects. - SFE-IV: School fixed effects and instrumental variables. - See text for details on the methods of estimation. 


\section{Appendix 1: The Sample of Countries}

Originally, 46 countries participated in TIMSS. As Argentina, Indonesia, and Italy were unable to complete the steps necessary to appear in the data base, Mexico chose not to release its results, and Bulgaria, the Philippines, and South Africa had insufficient data quality for the background data to be included in the international data base, performance and background datasets were available for 39 countries.

Data limitations made the implementation of our identification strategy impossible in a number of countries. Israel and Kuwait tested only eighth-grade students and no seventh-grade students. In Sweden, the seventh grade is in elementary schools, while the eighth grade is in secondary schools, so that there is no single school in the sample with both a seventh-grade and an eighth-grade class in it. Ninth-grade classes, which were additionally tested in both Sweden and Switzerland, could not be used as no information on grade-average class size was available for these classes. In England and Hungary, the question on grade-average class sizes was not administered in the schoolprincipal background questionnaire.

In a couple of countries, response rates on the class-size questions in the teacher and the school-principal background questionnaires were dismal. For example, data on the actual class size from the background questionnaires of the mathematics teachers were missing for 68 percent of the sampled students in Austria, 59 percent in Thailand, 53 percent in the Russian Federation, and 45 percent in Switzerland. Data on the gradeaverage class size from the background questionnaires of the school principals were missing for 44 percent of the sampled students in Norway and for 43 percent in Germany. Thus, the following countries were excluded because they had less than 50 schools left in either math or science for whom the appropriate data were available: Austria, Colombia, Cyprus, Denmark, Germany, Iran, Ireland, Latvia, Lithuania, Netherlands, New Zealand, Norway, Russian Federation, Slovak Republic, Switzerland, and Thailand.

This left us with our sample of 18 school systems: Australia, Flemish Belgium, French Belgium, Canada, Czech Republic, France, Greece, Hong Kong, Iceland, Japan, Korea, Portugal, Romania, Scotland, Singapore, Slovenia, Spain, and the United States. 


\section{Appendix 2: Robustness of the Results}

We checked our results for robustness against alternative specifications of the estimation equation and against peculiarities in the data. These robustness checks include using the log of class size, controlling for teacher characteristics, checking for imputed student- and family-background data, and checking for outliers.

The first alternative specification is to use a different functional form for the classsize/performance relationship. While the analysis before used a linear form - as, for example, also applied by Angrist and Lavy (1999), among many others - Hoxby (2000) suggests using the natural logarithm of class size, consistent with the observation that the proportional impact of a one-student reduction in class size is greater the smaller the initial size of the class. Tables A3 and A4 present the coefficients on the log of class size using each of the identification strategies applied above. As is apparent in columns (6) and (7), this adjustment produces only two noteworthy changes in our estimates generated using the SFE-IV method: In Korea in mathematics, the previously insignificant negative coefficient on class size becomes statistically significant at the 10 percent level, as does the positive coefficient on class size for science performance in Romania. A version of Figure 4 based on estimates using the $\log$ of class size would therefore contain an additional statistically significant result on each end of the distribution, bringing the total number of statistically significant estimates to five on the negative side and two on the positive. Our basic substantive conclusions regarding the magnitude of these effects, however, remain the same.

We also checked whether our results are robust to a specification that includes variables controlling for teacher characteristics. These characteristics are the sex, age, years of experience, and level of education of the specific mathematics and science teacher in each class in the TIMSS sample. Results from the re-estimation of our regressions with teacher controls included are presented in Tables A5 and A6. The figures in columns (17) and (18) confirm the lack of any substantive changes in our estimates of causal class-size effects produced by the SFE-IV method. The estimated coefficients on the vast majority of the teacher variables across countries do not reach statistical significance. This suggests that excluding the teacher controls in the initial specification seems warranted in order to preserve degrees of freedom. Among the 
statistically significant teacher results, there is no clear pattern in the coefficients on teacher's sex or age. The estimated coefficients on teaching experience are consistently positive, suggesting that, controlling for age, teacher's experience may have a positive impact on student achievement. The statistically significant coefficients on the different educational levels of the teacher are mostly positive in mathematics, although this pattern is less clear in science. It is important to emphasize, however, that any interpretation of these estimated coefficients on teacher characteristics needs to take into account that, like other resource inputs in education, they are potentially endogenous with respect to student performance (see Section V.F). Lacking good instruments for these variables, their inclusion provides only limited additional information about causal influences on student achievement.

The family-background data for which we control contain imputed values in cases where values were missing. The procedures used to generate these values are described in Wößmann (2000). While this allows for the inclusion of students for whom some family-background data was missing to have a full dataset for all participants in the test, the imputed values of the family-background data are no real data and might introduce uncertainties about the estimated effects. We have thus re-estimated the class-size effects under exclusion of all students with any missing value in the family-background data, which includes the data on the students' sex and age, the data on whether the student was born in the country and is living with both parents, and the data on parents' education and the number of books at home. The results of the re-estimation without imputed background data are presented in Tables A7 and A8. Column (1) reports the number of students with full original data. The exclusion rate relative to our original samples is highest at 19 percent in Greece (both in the mathematics and the science sample), and it is less than 1 percent in Japan and Singapore. As is obvious from columns (2) to (7) of Tables A7 and A8, no substantial changes in the results occur. To note, the significance level of the SFE-IV estimate for Greece in science drops to 11.5 percent, although the coefficient estimate remains within 0.21 of the previous result. In essence, the estimates of class-size effects excluding observations with imputed background data remain substantively the same.

In some countries, outliers of especially large or small classes are present in the dataset. It is not clear whether these outliers indeed represent actual large or small 
classes, or whether there are errors in the data. There are reasons for especially large or small classes to exist in reality. In small villages, a student cohort might by chance be especially small, which would result in an especially small class size. Likewise, chronic illness of teachers might lead to particularly large classes in special cases. Very large classes do exist in a lot of countries, and this class-size variation might reasonably be used to estimate class-size effects. Nevertheless, it is always possible that outlying cases in the dataset are caused by misunderstandings of questionnaire items on part of the teacher or the school principal, by mistakes in writing when filling in the questionnaires, or simply by typing errors in the construction of the database. As we cannot tell whether an error exists in any particular case, we chose to leave any outlying cases in the database for our estimations. However, to check whether any of our results are driven by such outliers, we went through the data for each country and subject, excluded any obvious outliers, and re-estimated our results. None of the results changed in any substantial way, so that we can be confident that our results are not driven by any outliers. In a few instances, the number of students in the database who were actually tested in a class was larger than the class size reported by the teacher. We replaced the reported class size by the number of tested students in these cases, continuing to leave out any outliers. Again, this had no noteworthy impact on our results. 


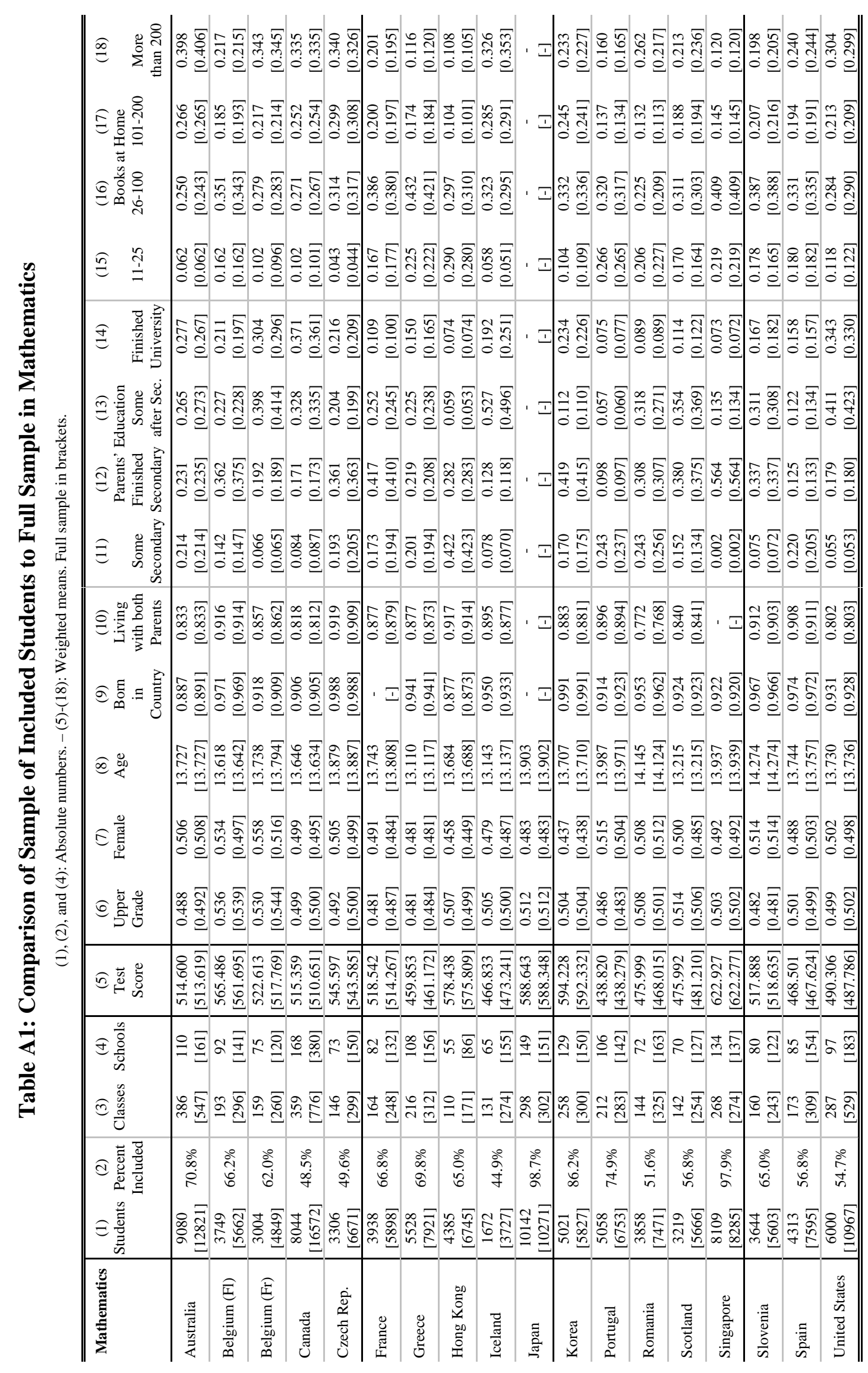




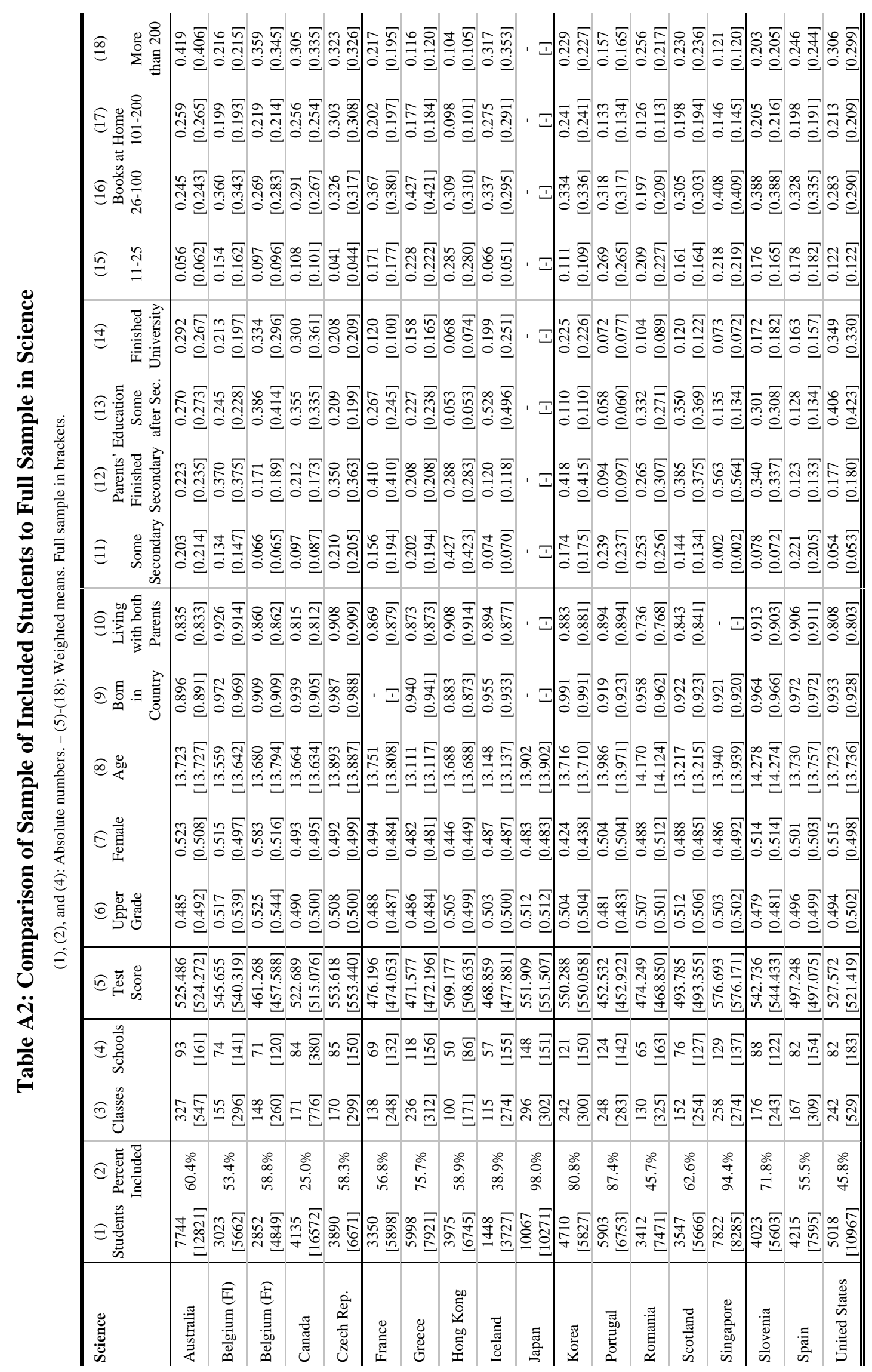




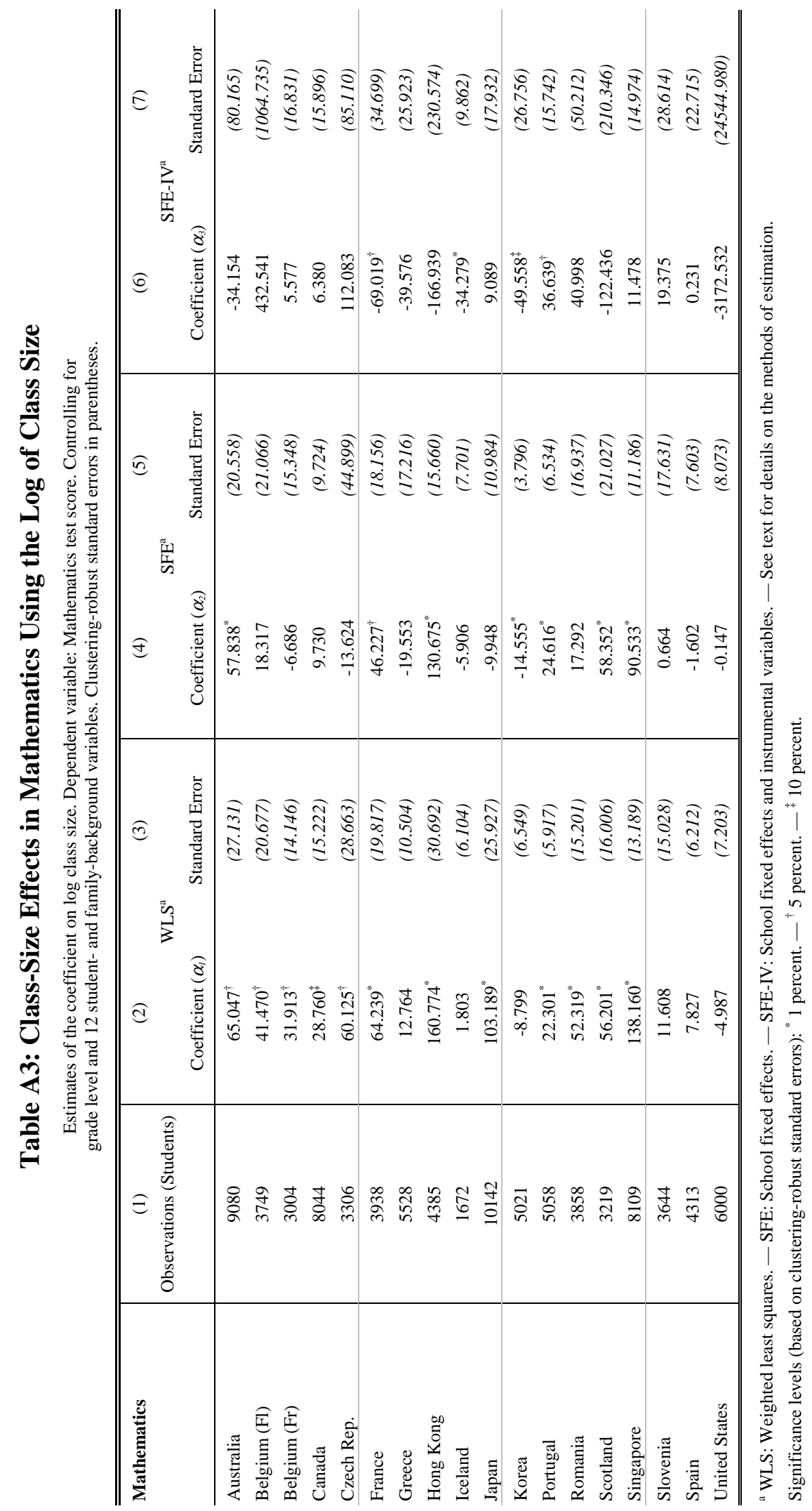




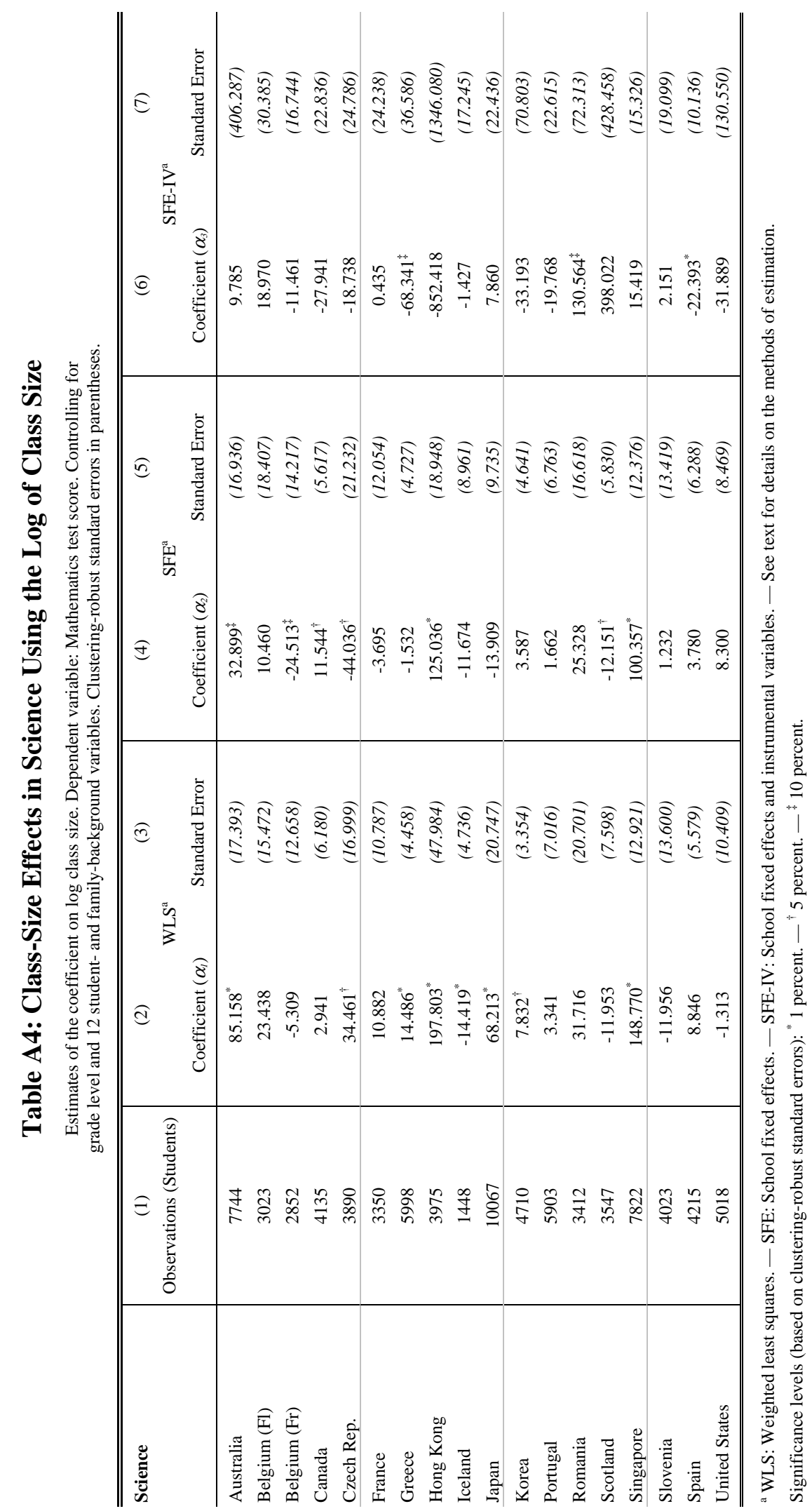




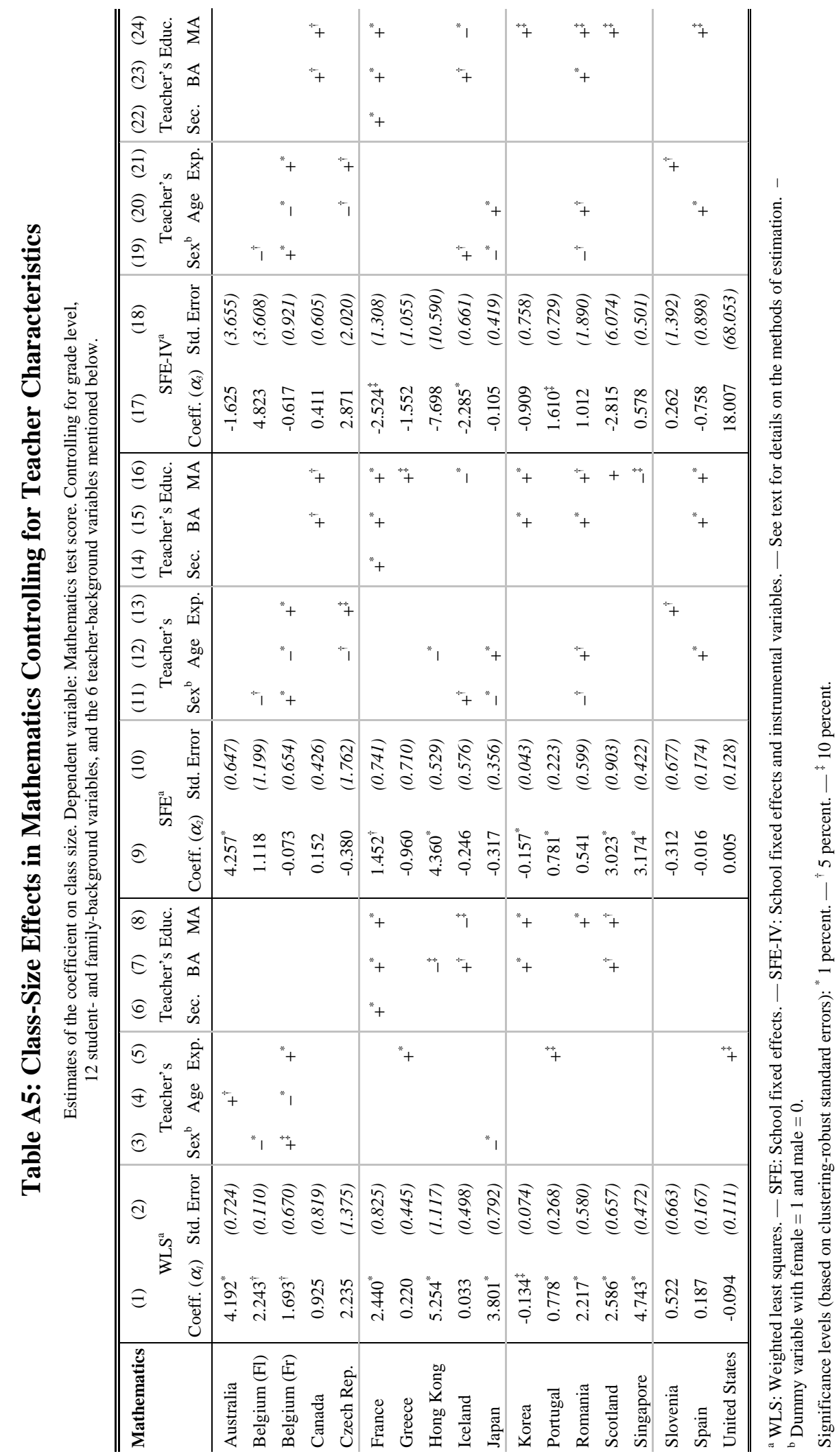




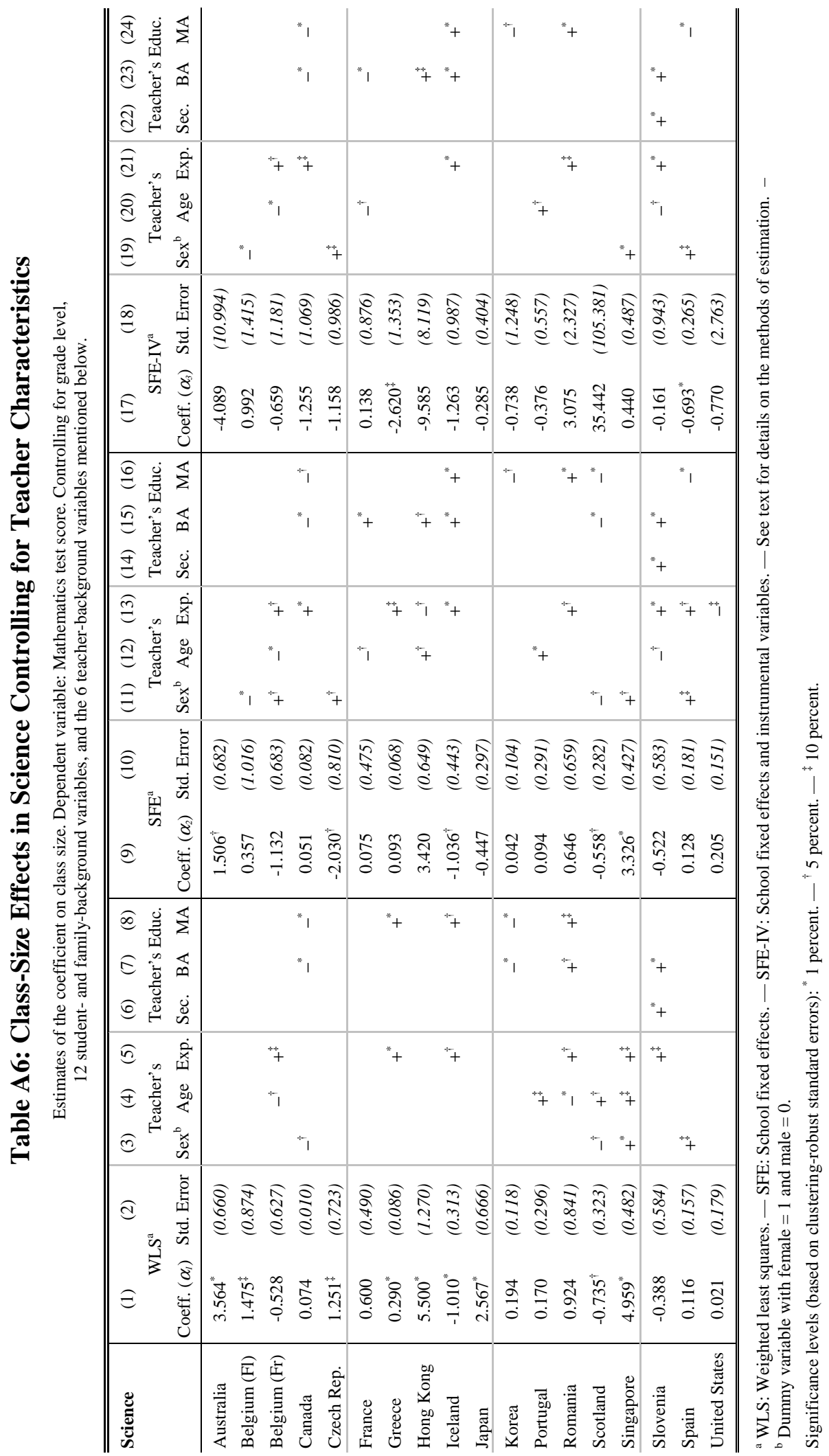




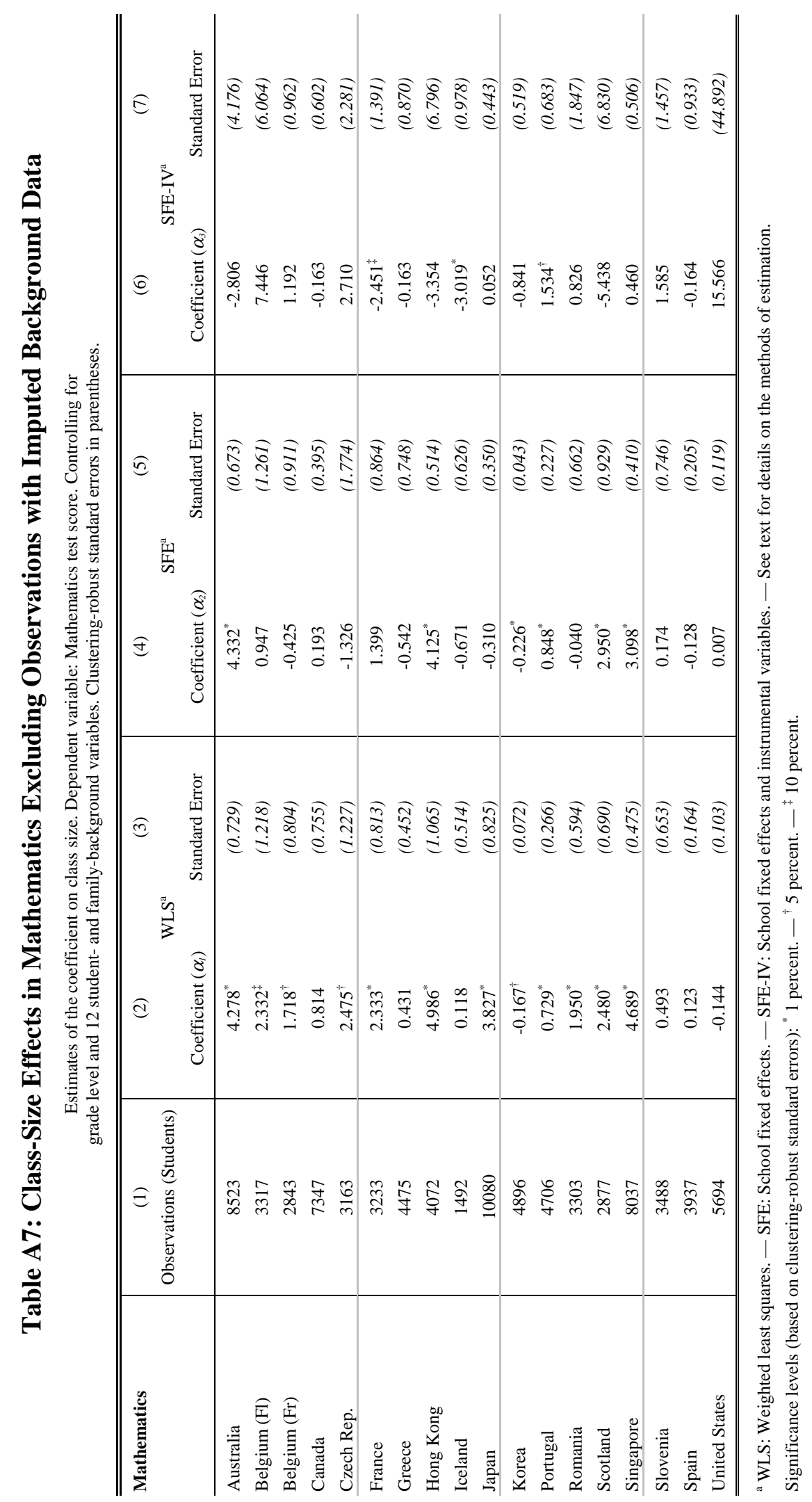




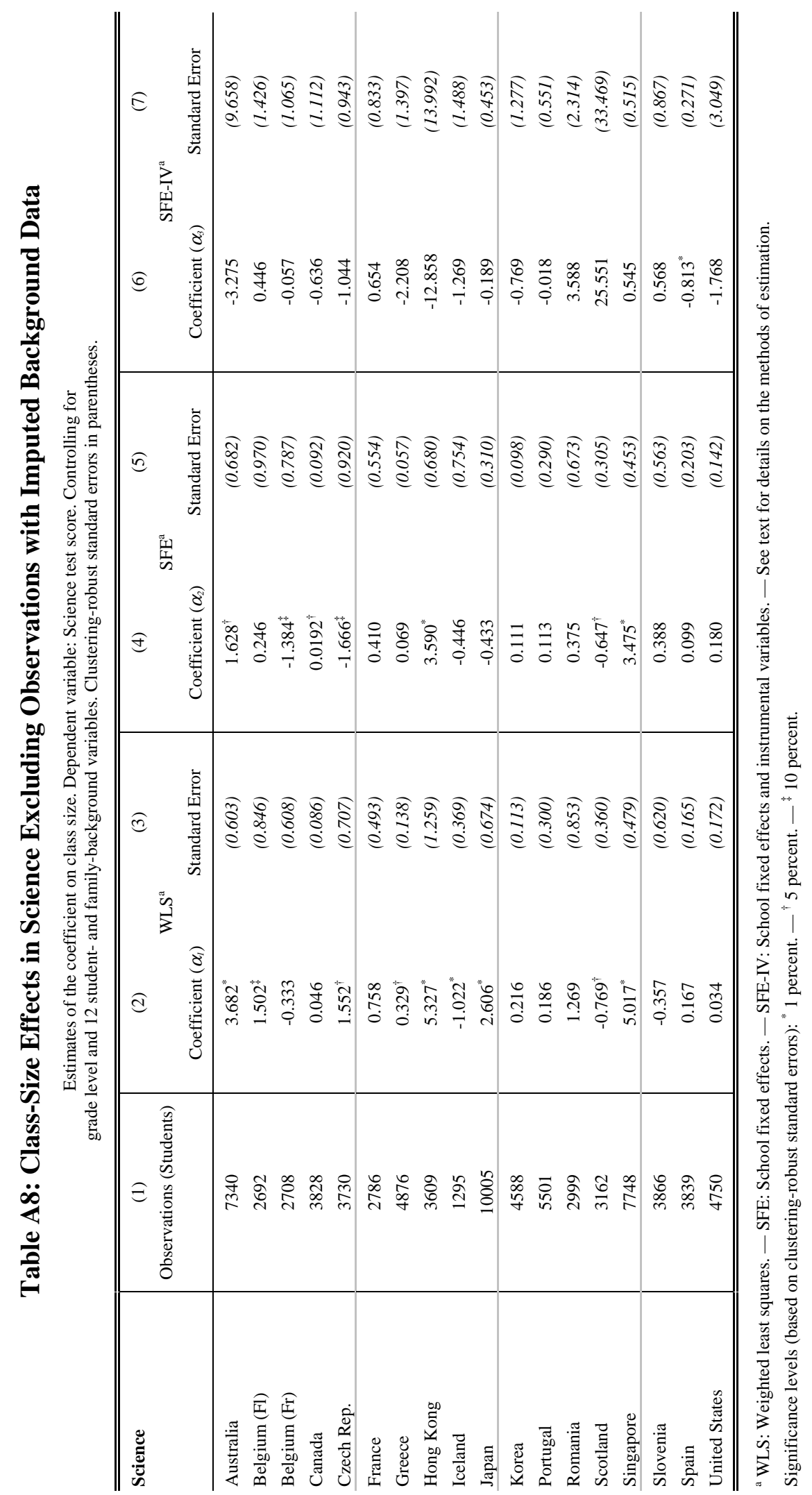




\section{IZA Discussion Papers}

No. Author(s)

469

R. Lalive

J. C. van Ours

J. Zweimüller

470
A. Cigno
F. C. Rosati
L. Guarcello

471

B. R. Chiswick

Y. Liang Lee

P. W. Miller

472 R. Foellmi

J. Zweimüller

473

J. C. van Ours

474

J. T. Addison

L. Bellmann

A. Kölling

475

Z. Hercowitz

E. Yashiv

W. A. Cornelius

T. Tsuda

M. A. Clark

D. A. Jaeger

H. Gersbach

A. Schniewind

J. T. Addison

C. R. Belfield

G. Saint-Paul

481

482

483

484

J. H. Bishop

L. Woessmann

485

E. Schlicht

P. Kuhn

C. Weinberger

H. Rapoport

A. Weiss

L. Woessmann
Title

The Effect of Benefit Sanctions on the Duration of Unemployment

Does Globalisation Increase Child Labour?

Immigrants' Language Skills and Visa Category

Structural Change and the Kaldor Facts of

Economic Growth

A pint a day raises a man's pay, but smoking blows that gain away

Unions, Works Councils and Plant Closings in

Germany

A Macroeconomic Experiment in Mass

Immigration

Labor Market Incorporation of Immigrants in Japan and the United States: A Comparative Analysis

Natives, the Foreign-Born and High School Equivalents: New Evidence on the Returns to the GED

Uneven Technical Progress and Unemployment 3

Unions and Employment Growth: The One

Constant?

The Complexity of Economic Policy:

I. Restricted Local Optima in Tax Policy Design

M. R. West
Hiring Standards and Market Clearing

Leadership Skills and Wages

In-Group Cooperation in a Hostile Environment:

An Economic Perspective on Some Aspects of

Jewish Life in (Pre-Modern) Diaspora

Institutional Effects in a Simple Model of

Educational Production

Class-Size Effects in School Systems Around the World: Evidence from Between-Grade

Variation in TIMSS
2

1

04/02

3

04/02

5

Area

Date

3

04/02

04/02

04/02

04/02

04/02

04/02

04/02

04/02

04/02

04/02

04/02

04/02

04/02

04/02

5

04/02

An updated list of IZA Discussion Papers is available on the center's homepage www.iza.org. 